\title{
The Self-Fulfilling Nature of Positive Illusions in Romantic Relationships: Love Is Not Blind, but Prescient
}

\author{
Sandra L. Murray \\ University of Michigan
}

\author{
John G. Holmes \\ University of Waterloo
}

\author{
Dale W. Griffin \\ University of Sussex
}

\begin{abstract}
It is proposed that satisfying, stable relationships reflect intimates' ability to see imperfect partners in idealized ways. In this study of the long-term benefits ( or possible costs) of positive illusions, both members of dating couples completed measures of idealization and well-being 3 times in a year. Path analyses revealed that idealization had a variety of self-fulfilling effects. Relationships were most likely to persist - even in the face of conflicts and doubts - when intimates idealized one another the most. Intimates who idealized one another more initially also reported relatively greater increases in satisfaction and decreases in conflicts and doubts over the year. Finally, individuals even came to share their partners' idealized images of them. In summary, intimates who idealized one another appeared more prescient than blind, actually creating the relationships they wished for as romances progressed.
\end{abstract}

Love to faults is always blind,

Always is to joy inclin'd,

Lawless, wing'd, and unconfin'd,

And breaks all chains from every mind.

-William Blake, Poems (1791-1792) from Blake's Notebook

Reality or parody? In many ways, Blake's musings depict the romantic ideal. Swept up in the experience of love, trusting, satisfied individuals embellish their partners' virtues, while charitably, perhaps sensibly, turning a blind eye to their faults (e.g., Murray \& Holmes, 1993, 1994). Setting Blake's ideal aside, most psychologists believe that lasting satisfaction depends on individuals understanding their partners' real strengths and frailties (e.g., Brickman, 1987; Swann, De La Ronde, \& Hixon, 1994; Swann, Hixon, \& De La Ronde, 1992). After all, because

Sandra L. Murray, Department of Psychology, University of Michigan; John G. Holmes, Department of Psychology, University of Waterloo, Waterloo, Ontario, Canada; Dale W. Griffin, Department of Cognitive and Computing Sciences, University of Sussex, Falmer, Brighton, England.

This article is based on a doctoral dissertation submitted by Sandra L. Murray to the University of Waterloo. The article was prepared with the support of a Social Sciences and Humanities Research Council of Canada (SSHRC) Postdoctoral Fellowship and two SSHRC research grants.

We are greatly indebted to Harry Reis and Mark Zanna for their thoughtful comments on this research. We would also like to thank Mary Dooley for her assistance in conducting this research.

Correspondence concerning this article should be addressed to Sandra L. Murray, who is now at the Department of Psychology, Park Hall, State University of New York, Buffalo, New York 14260-4110. Electronic mail may be sent via the Internet to smurray@acsu.buffalo.edu. few individuals really are perfect, time should inevitably reveal just how romantic partners fall short of each others' hopes. Upon such realizations, lovers should then end up disappointed and disillusioned.

Do positive illusions inevitably breed discontent? Or might idealization actually promote later happiness? For instance, seeing a partner's faults through the rosy filters provided by one's ideals might minimize the potential for conflict. Intimates might even create the interpersonal realities they desire by idealizing their partners (e.g., Snyder, Tanke, \& Berscheid, 1977). In such ways, idealization might actually insulate intimates against the vicissitudes of time rather than set them up for disappointment. In this article we examine these issues, focusing on the long-term benefits (and possible costs) of positive illusions in dating relationships.

\section{Seeking Security: The Idealization Process}

Positive illusions may be a romantic necessity. Consider the dilemma individuals face as a romance develops. The allure of a partner's virtues draws intimates into relationships, creating feelings of hope and security that belie the lack of more representative experiences (e.g., Brehm, 1988; Brickman, 1987). Later, interaction across broader, more conflictual domains reveals a partner's frailties (e.g., Braiker \& Kelley, 1979; Levinger, 1983). Even in marriage, intimates may continue to uncover sources of negativity and conflict as new demands surface, such as balancing children and career. These inevitable disappointments may then threaten feelings of security by raising the fear that one's partner really isn't the "right" person after all.

Such doubts are troublesome for most intimates, precisely because negativity typically surfaces when their hopes are al- 
ready invested in their relationships. To add a further irony, individuals may only discover a partner's more serious faults when the barriers to dissolution have also increased (e.g., a perceived lack of alternative partners, the arrival of children). In the face of this "romantic trap," individuals need to reach some sort of cognitive resolution between their hopes and doubts in order to justify their continuing commitments (e.g., Abelson, 1959; Epstein, 1982; Festinger, 1957). Apart from seeking cognitive clarity, individuals may also struggle to quell feelings of emotional vulnerability (e.g., Baumeister \& Leary, 1995; Holmes \& Rempel, 1989). For example, attachment theorists contend that individuals are strongly motivated to seek feelings of safety and security in their relationships (e.g., Bowlby, 1977, 1982). But such attachment concerns are frustrated by intimates' perceptions of the risks posed by depending on a less than perfect partner.

Accurately understanding a partner's real weaknesses may do little to resolve the tension between intimates' hopes and fears. What comfort is to be gained from the knowledge that one's partner is both inexpressive and stubborn? Instead, sustaining a sense of felt security may necessitate weaving an elaborate story (or fiction) that both embellishes a partner's virtues and minimizes his or her faults (Murray \& Holmes, 1993, 1994). For instance, Hillary might quell her disappointment in Bill's inexpressiveness by regarding it as a sign of his strong and silent nature. Or she might try to compensate for this fault by embellishing Bill's tolerance.

Given such motivations and the poetic license inherent in the storytelling process, trusting, satisfied intimates should come to see their partners in quite idealized ways (e.g., Hall \& Taylor, 1976; Johnson \& Rusbult, 1989; Murray \& Holmes, 1993, 1994; Simpson, Ickes, \& Blackstone, 1995; Van Lange \& Rusbult, 1995). However, if intimates are even reasonably accurate social perceivers, a partner's actual qualities should also constrain perception. After all, only characters in fairy tales can actually turn frogs into princes or princesses. Put a different way, some combination of illusion (or motivated misunderstandings) and reality (or understanding) likely underlies individuals' perceptions of their partners, as the following equation illustrates:

\section{Actor's Perceptions $=$ Partner's Reality + Actor's Illusion.}

For example, Hillary's perception of Bill should partly reflect her knowledge of Bill's real qualities and partly reflect her "illusions" or hopes. We recently examined this hypothesis in samples of dating and married couples (Murray, Holmes, \& Griffin, 1996). In this study, intimates rated themselves, their own partners, their ideal partner, and the typical partner on a variety of virtues and faults (e.g., "responsive," "critical"). We then created indices of "illusory" and "reality-based" components of perception using the benchmarks just described. To continue with our original example, the actor's (Hillary's) perceptions referred to her ratings of Bill. The partner's (Bill's) reality referred to Bill's ratings of himself. The actor's (Hillary's) illusions referred to the qualities that Hillary saw in Bill that Bill did not see in himself-a residualized measure of illusions (Hillary's perception of Bill, controlling for his perception of himself).'

As hypothesized, impressions of a partner appeared to reflect a mixture of "reality" and "illusion" in both dating and marital relationships. The partner's actual or self-perceived qualities did play a limited role in shaping the actor's perceptions. Individuals with more positive self-concepts were also held in high regard by their partners, whereas the opposite was true for individuals with more negative self-concepts. But even among married couples, these "understanding" or accuracy correlations were only moderate in size, raising the possibility that some degree of positive illusion (or motivated misunderstanding) also shaped perceptions.

\section{Projecting Self and Ideals}

If the desire for security motivates idealization, certain hopes or wishes should shape the nature of these motivated misunderstandings. For instance, believing a partner mirrors one's image of the ideal partner may allow one to feel safe and secure in one's commitment (e.g., Murstein, 1967, 1971). Also, seeing oneself in one's partner may foster a sense of predictability and assumed similarity critical for feeling secure (Holmes \& Rempel, 1989). Our cross-sectional study (Murray et al., 1996) revealed that individuals' self-images and schemas for the ideal partner appeared to shape their illusions: The more positive their ideals and self-images, the more idealized their impressions of their partners.

Furthermore, working models of self and other were closely tied, as attachment theorists have argued (e.g., Bowlby, 1982). Individuals with a stronger sense of self-worth set higher ideals and perceived more virtues in their partners, whereas individuals with a weaker sense of self-worth expected less from an ideal partner and perceived fewer virtues in their own partners. Thus, individuals more secure in their own sense of self were more generous in their depictions of their partners, overlooking faults and embellishing virtues. Conversely, the projection of personal insecurities appeared to interfere with intimates seeing the best in their partners (e.g., Karney, Bradbury, Fincham, \& Sullivan, 1994).

It is important to note that this evidence for projection transcended the effects of actual similarity. That is, intimates with higher self-esteem were not any more likely to have partners with high self-esteem. So the link between rosy self-images and idealization cannot be explained by these individuals having partners who are easier to idealize. Nor did the evidence for projection simply reflect a Pollyanna effect. We still found strong evidence for idealization even when we controlled for individuals' general tendency to see others in more or less positive terms. Most critical, we found this evidence for positive illusions using a reality benchmark (the partner's self-perceptions) that was already colored by a degree of self-enhancement (e.g., Taylor \& Brown, 1988).

\footnotetext{
${ }^{1}$ At this point a caveat is in order. In using Bill's self-perceptions as a "reality" benchmark, we are not arguing that individuals possess true insight into the actual nature of their own attributes. Instead; numerous studies suggest that individuals' self-perceptions are colored by some degree of positive illusion (e.g., Alicke, 1985; Brown, 1986; Greenwald, 1980; Taylor \& Brown, 1988). But given this evidence of self-aggrandizement, self-perceptions may prove a very conservative benchmark for indexing a partner's illusions (i.e., Hillary's illusions about Bill must transcend his own illusions about himself). Further, using a partner's self-perceptions as a baseline operationally defines the concept of "understanding," which has been central in theoretical debate.
} 


\section{Constructing Security}

A sense of relationship security and well-being does indeed appear to necessitate a certain degree of illusion (or inaccuracy). Our cross-sectional study (Murray et al., 1996) revealed that individuals were more satisfied in their relationships when they saw virtues in their partners that their partners did not see in themselves-a "projected illusions" effect. Being idealized also benefited well-being. That is, individuals were happier in their relationships when their partners looked beyond the "reality" of their self-perceived frailties and saw the best in them-a "reflected illusions" effect. Accurately understanding a partner's self-views rarely predicted satisfaction, in contrast to Swann et al.'s (1992, 1994) views on the benefits of self-verification. When it did, intimates were actually less happy when they agreed with their partners' relatively negative self-views. Instead, systematic inaccuracies - in the form of positive illusions-predicted greater, concurrent happiness among both dating and married couples (Murray et al., 1996).

\section{A Permanent Peace? The Disappointment Model}

It is the expectation of seeing [one's beloved] that has produced this unpleasant effect . . . What happens is that the imagination, violently wrenched out of delicious reveries in which every step brings happiness, is dragged back to stern reality.-Stendhal, $O n$ Love

Positive illusions, then, afford at least a temporary sense of security or peace. But Stendhal's musings suggest that such imaginative reveries are ultimately betrayed by sterner realities. Attesting to this pessimistic perspective, C. Kelly, Huston, and Cate (1985) found that engaged intimates who were initially most in love actually suffered the greatest declines in love after marriage. Further illustrating the possible perils of blind idealization are findings that conflicts that typically have little bearing on reports of love and satisfaction prior to marriage predict declines in satisfaction after marriage (Braiker \& Kelley, 1979; C. Kelly et al., 1985; Markman, 1979, 1981 ). Such findings suggest that the benefits of understanding a partner's real qualities may only surface later in romances, when such realism protects intimates from disappointment.

Positive illusions then might only provide a false sense of security that actually creates (or at least heightens) the potential for eventual disappointment and distress. As one possible mechanism for such "self-defeating" effects, idealizing a partner might blind intimates to real difficulties or incompatibilities, such as differing desires for closeness versus distance (e.g., Christensen \& Heavey, 1993). Viewing partners through the rosy filter provided by their ideals, individuals may simply assume compatibility on such dimensions even where latent conflicts exist. Holding high, perhaps unrealistic, ideals might also contribute to later disappointment when increased interdependence reveals how a partner falls short of such standards (e.g., Higgins, 1987). Finally, a partner's faults may begin to appear less endearing or excusable when such initial, charitable construals are put to the test over time. The struggle to adapt to violated hopes and newly discovered differences may then heighten conflicts and reports of ambivalence. In contrast, intimates who more accurately understand their partners' real attributes may experience a more lasting sense of security (e.g.,
Swann et al., 1994). For instance, accurately understanding differences in personalities or needs should facilitate adjustment, thereby preempting later difficulties and ensuring continued satisfaction.

Just as idealizing a partner may pose certain long-term risks, the benefits of being idealized might also begin to fade as time passes. Intimates might begin to resent the burden of living up to their partners' idealized images of them (even if such positive regard once predicted greater well-being). Swann and his colleagues argued that individuals in longer-term relationships want their partners to understand and validate their "real" qualities. Even though dating individuals were happier when their partners idealized them, Swann et al. (1994) found that married individuals resisted such groundless flattery and were actually happier when their partners saw them as they saw themselves. Such findings suggest that accurately understanding a partner's qualities may be increasingly critical for continued satisfaction as romances progress.

\section{A Self-Fulfilling Prophecy? The Wish-Fulfillment Model}

Such a perspective, however, ignores the link between positive illusions and satisfaction in marriage that we reported earlier (Murray et al., 1996). Despite the rigors of time, married intimates were happier when they idealized one another, not when they more accurately understood one another. Also, other studies have shown that dating relationships are more likely to persist and stay satisfying when intimates see their partners as much more desirable than any other conceivable partner (Felmlee, Sprecher, \& Bassin, 1990; Johnson \& Rusbult, 1989; Simpson, 1987). Such findings suggest that idealization may promote continued satisfaction and stability as dating relationships progress. Why might this be the case?

Positive illusions may act as a resource of goodwill or confidence that actually allows intimates to cope more effectively with (or at least tolerate) disappointments as time passes. For example, intimates are better able to weather feelings of ambivalence if their commitment is sufficiently strong ( Thompson \& Holmes, 1995). Even in marriage, positivity appears to regulate or moderate the effects of negativity. Married intimates are more likely to remain committed and happy as long as positive interactions outweigh negative ones by a ratio of at least five to one (Gottman, 1994; Gottman \& Levenson, 1992). Newlywed wives were also less disturbed by their husbands' complaints when they occurred in the context of a warm, affectionate relationship (Huston \& Chorost, 1994). We predict that positive illusions will play a similar role in insulating dating intimates from the harmful effects of conflict and doubt-the buffering hypothesis.

As a further possible mechanism for such "self-fulfilling" effects, idealizing a partner may motivate intimates to transform the meaning of apparent faults or conflicts and thus diminish their significance (e.g., Kelley, 1979). For instance, seeing a partner's behaviors through the rosy filters provided by one's ideals may encourage tolerance in the face of transgressions (e.g., Rusbult, Verette, Whitney, Slovik, \& Lipkus, 1991 ). When conflicts do occur, seeing a partner's faults in the best possible light may provide intimates with the optimism necessary to confront problems. Also, coming to terms with a partner's frailties by linking them to greater virtues may lessen the 
likelihood that individuals will later experience renewed ambivalence or doubts about these imperfections. In such ways, idealizing a partner may ward off later threats and minimize the chances of intimates experiencing significant conflicts or entertaining serious doubts-the transformation hypothesis.

Furthermore, individuals might even create the interpersonal realities they desire by idealizing their partners. Interactions with intimate others are thought to shape and expand individuals' self-concepts, particularly in domains, such as developing romances, where self-knowledge may be uncertain (e.g., Aron, Aron, Tudor, \& Nelson, 1991; Aron, Paris, \& Aron, 1995; Baumeister \& Tice, 1986; M. R. Leary, Tambor, Terdal, \& Downs, 1995; Schlenker, 1986; Tice, 1992). If this is the case, intimates may continue to bask in the glow of their partners' reflected appraisals as time passes-coming to share aspects of their partners' idealized views of them - rather than stubbornly clinging to less desirable self-images (e.g., Swann et al., 1992). Such effects might emerge because individuals come to see their own attributes through their partners' (more forgiving) eyes. Individuals might even directly contradict their partners' selfdoubts or criticisms, thereby bolstering their partners' sense of self-worth. Intimates might also encourage their partners to live up to their idealized standards simply by treating their partners as special, unique individuals (e.g., Snyder \& Swann, 1978; Snyder et al., 1977). Accordingly, we predict that intimates can actually turn self-perceived frogs into the princes or princesses they perceive them to be-the reflected appraisal hypothesis.

\section{A Role for Reality: Working Models of Self}

Despite the potential for such "self-fulfilling" effects, certain realities may penetrate intimates' defenses as dating relationships progress-precisely because of the link between models of self and others (Murray et al., 1996). As we discussed, dispositional insecurities interfere with intimates seeing their partners in the most flattering light. That is, individuals with more negative models of self (i.e., lower self-esteem) are less likely to idealize their partners and, as a consequence, might be less likely to treat them well. For instance, Karney et al. (1994) found that married intimates prone to negative affect are also more likely to make blaming or accusatory attributions in their interactions with their spouses. Similarly, more neurotic married intimates are involved in more dissatisfying and less stable relationships (E. L. Kelly \& Conley, 1987). Such results suggest that intimates' continued ability to idealize their partners should depend on their own level of self-esteem but-and this is most critical-should also be constrained by their partners' level of self-regard. That is, intimates should experience increasing difficulty idealizing a partner whose words (and perhaps deeds) belie such positive regard. In summary, the passage of time should exacerbate the effects of self-esteem, ultimately constraining the link between positive illusions and well-being.

\section{Summary of Hypotheses}

If positive illusions only set the stage for disillusionment, idealizing a partner should forecast later relationship distress and dissolution. And more accurately understanding a partner's "real" qualities should protect satisfaction and ward off later difficulties. But if positive illusions actually have self-fulfilling (rather than self-defeating) effects, romances should persist and become relatively more satisfying when intimates idealize one another the most. We predict that idealization will have such self-fulfilling effects because of its role in buffering intimates from the harmful effects of early doubt and conflict (the buffering hypothesis), in bolstering later satisfaction and reducing later conflicts and ambivalence (the transformation hypothesis), and in actually turning intimates into the special individuals their partners perceive (the reflected appraisal hypothesis). Finally, because of the concurrent link between self-esteem and interpersonal generosity, we expect that positive models of self will prove critical in sustaining positive illusions and well-being over time.

\section{Method}

\section{Overview}

To examine how positive illusions shaped developing romances, we followed a sample of 121 dating couples over the course of 1 year. At Time 1, individuals described themselves, their partner, their ideal partner, and the typical partner on a variety of interpersonal attributes. Each individual also completed measures of relationship well-being (e.g., satisfaction, ambivalence, and conflict). We recontacted these couples 45 months after the initial session (Time 2) and again 11-12 months after the initial session (Time 3). At each follow-up, we asked respondents who were still together to complete a shortened version of the Time 1 questionnaire.

\section{Participants and Procedure}

Initial session. Participants were 121 dating couples who participated in a study of "Thoughts and Feelings in Dating Relationships" held at the University of Waterloo. Fifty-five of these couples participated in the cross-sectional study reported in Murray et al. (1996). The majority of couples $(N=118)$ described themselves as dating their partners exclusively. The participants' mean age was 19.5 years, and they had been dating 19.0 months on average.

If both members of the couple were present in the lab, they were seated at separate tables and completed the questionnaires independently. If only one member of the couple could attend the lab session, their partners were sent questionnaires and letters inviting them to participate in the study. Again, individuals were cautioned to complete the questionnaire without discussing their responses with their partners. Respondents received either course credit or $\$ 6$ for participating.

Follow-ups. At Times 2 and 3, a female research assistant individually contacted each of the members of the dating couples by phone. She first asked whether the respondent was still dating the same person. If the relationship was intact, she asked respondents to complete a short questionnaire on their thoughts and feelings about their relationships. If respondents agreed, a questionnaire and a stamped and addressed return envelope were mailed to them. Upon receipt of the questionnaire, participants were paid $\$ 6$ and promised a summary of the research findings.

Out of the original sample of 121 couples, 116 couples were recontacted and agreed to participate in at least one of the follow-ups. One couple declined the invitation to participate, and 4 couples could not be located. Over the year, 43 couples dissolved their relationships (approximately $35 \%$ of the sample). At Time 2, 92 couples were still dating and at least one member of each couple agreed to complete the follow-up. Both members of 73 couples returned Time 2 measures. One member of 17 couples returned the measures, and 2 couples did not return the measures. At Time 3,73 couples were still dating and at least one member of each couple agreed to complete the follow-up. Both members of 58 couples returned Time 3 measures. One member of 
13 couples returned the measures, and 2 couples did not return the questionnaires.

\section{Measures}

Both the initial and follow-up questionnaires included measures of (a) models of self and other, including measures of self-perceptions and perceptions of individuals' own partners, the typical partner, and the ideal partner, and (b) relationship well-being (e.g., satisfaction, ambivalence, and conflict). All questionnaires asked for the respondent's gender, age, and relationship length. These measures are described below. Any differences in questionnaire content across the time periods are also described.

Interpersonal Qualities Scale. In developing this measure of self and other models, we selected positive and negative attributes from the interpersonal circle (e.g., T. Leary, 1957; Wiggins, 1979), a model based on the primary dimensions of warmth-hostility and dominance-submissiveness. Example attributes included "kind and affectionate," "open and disclosing," "responsive to my needs," "tolerant and accepting," "understanding," "patient," "critical and judgmental," "controlling and dominant," "thoughtless," "distant and complaining," and "irrational." We also selected a number of attributes often considered to represent commodities in the social-exchange process (e.g., Rubin, 1973), such as "sociable," "self-assured," "intelligent," "witty," and "lazy." In computing the trait-perceptions index, negative traits were reverse-scored, such that higher scores represented more favorable perceptions.

To provide baselines for assessing positive illusions, we asked participants to describe themselves, their own partners, the ideal partner, and the typical partner on this attribute measure ( see Murray et al., 1996, for further details). Participants rated how well each of the traits described the target (e.g., self, partner, typical, ideal) on a 9-point scale ( 1 $=$ not at all characteristic, $9=$ completely characteristic). The order of the attribute ratings for the different targets was partially counterbalanced across participants. We analyzed this scale in two ways, examining both individuals' total scores (a nomothetic approach) as well as their personality profiles (an idiographic approach).

Self-esteem. At Time 1, participants also completed Rosenberg's (1965) 10-item Self-Esteem Scale to provide a measure of their global self-evaluations (e.g., "I feel that I am a person of worth, at least on an equal basis with others"). Participants responded to such items on a 4point scale $(1=$ strongly disagree, $4=$ strongly agree $)$.

Attachment style. At Times 1 and 3, participants completed Bartholomew and Horowitz's (1991) Attachment Styles Questionnaire. This scale consists of four paragraphs, each describing a prototypic attachment pattern (fearful, preoccupied, secure, and dismissing). Participants rated how well each prototype described them on 7-point scales; this allowed us to create indices of the positivity of models of self ("secure" and "dismissing" ratings minus "fearful" and "preoccupied" ratings) and models of other ("secure" and "preoccupied" ratings minus "dismissing" and "fearful" ratings; see Griffin \& Bartholomew, 1994).

Satisfaction. The 4-item satisfaction scale indexed participants' global evaluation of their relationships (e.g., "I am extremely happy with my relationship; I have a very strong relationship with my partner"). Participants responded to these (and all following) items on 9-point scales ( $1=$ not at all true, $9=$ completely true $)$.

Ambivalence. The 4-item ambivalence scale (adapted from Braiker \& Kelley, 1979) captured individuals' experience of conflicted or confused feelings about their relationships (e.g., "I feel somewhat confused about my feelings toward my partner").

Conflict-negativity. The 5-item conflict scale (adapted from Braiker \& Kelley, 1979) indexed the frequency of overt behavioral conflict and direct communications of negative affect (e.g., "Our arguments often involve quite serious problems or issues").

Destructive conflict styles. This 23 -item scale indexed chronic ten- dencies to deal with problems through (a) avoidance (e.g., "My partner sometimes avoids discussing problems in our relationship because he/ she is afraid of hurting me"), (b) reciprocal cycles of criticism and blame (e.g., "If I criticize my partner, my partner tends to criticize me in return"), and (c) constructive engagement (reverse-scored; e.g., "When I act in an angry or hurtful way, my partner tries to find out what is bothering me rather than acting angry and hurt too"). Higher scores indicated more destructive conflict styles. A 9-item version of this scale was used in the follow-ups.

Trait ambivalence. This 8-item scale (administered at Time 3) indexed individuals' experience of conflicted feelings about the actual merit of their partners' attributes (e.g., "kind and affectionate," "tolerant and accepting"). Individuals rated each attribute on two dimensions, first rating how "beneficial" the attribute was and second rating how "harmful" it was. Ambivalence was computed according to the following formula developed by Thompson, Zanna, and Griffin (1995):

Ambivalence $=($ beneficial + harmful $) /$

$$
2 \text { - absolute value (beneficial - harmful). }
$$

\section{Results}

To explore the self-fulfilling (or self-defeating) effects of idealization and understanding, we centered our analyses in two main areas. We first examined the concurrent link between positive illusions, understanding, and well-being, replicating and extending our previous work (Murray et al., 1996). We then conducted a series of longitudinal analyses. The first set explored the link between positive illusions and dissolution (the buffering hypothesis). The second set examined changes in well-being as a function of idealization (the transformation hypothesis). The third set examined whether intimates can create the partners they desire by idealizing them (the reflected appraisal hypothesis). And the final set examined the possibly self-corrective nature of idealization, that is, how individuals adjust their working models of actual and ideal partners to reality as time passes.

Table 1 presents the reliabilities, means, and standard deviations for each variable for men and women at each time period. Individuals' mean ratings of themselves and their partners on the Interpersonal Qualities Scale indexed the overall positivity of partners' realities and actors' impressions, respectively. In computing this trait-perceptions index, we reverse-scored negative traits, such that higher scores represented more favorable perceptions.

\section{Analytic Strategy: Indexing "Illusion" and "Reality"}

Structural equation modeling with a maximum likelihood program such as LISREL, EQS, or CALIS allows the simultaneous estimation of path coefficients in a number of different equations. We first defined the male's perception of the female as part reality, part projection, and part unexplained variance or error. Similarly, we defined the female's perception of the male as part reality, part projection, and part unexplained variance or error. This model of actors' perceptions is represented by the following set of equations:

Male's Perception of Female $=\beta_{1}$ Female Self

$$
+\beta_{2} \text { Male Self }+\beta_{3} \text { Male's Ideal }+ \text { Error } 1
$$

Female's Perception of Male $=\beta_{4}$ Male Self

$$
+\beta_{5} \text { Female Self }+\beta_{6} \text { Female's Ideal }+ \text { Error } 2 \text {. }
$$


Table 1

Reliabilities, Means, and Standard Deviations of Each Variable at Times 1, 2, and 3

\begin{tabular}{|c|c|c|c|c|c|c|c|c|c|c|c|c|c|c|c|}
\hline \multirow[b]{3}{*}{ Measure } & \multicolumn{5}{|c|}{ Time 1} & \multicolumn{5}{|c|}{ Time 2} & \multicolumn{5}{|c|}{ Time 3} \\
\hline & \multirow[b]{2}{*}{$\alpha$} & \multicolumn{2}{|c|}{ Men } & \multicolumn{2}{|c|}{ Women } & \multirow[b]{2}{*}{$\alpha$} & \multicolumn{2}{|c|}{ Men } & \multicolumn{2}{|c|}{ Women } & \multirow[b]{2}{*}{$\alpha$} & \multicolumn{2}{|c|}{ Men } & \multicolumn{2}{|c|}{ Women } \\
\hline & & $M$ & $S D$ & $M$ & $S D$ & & $M$ & $S D$ & $M$ & $S D$ & & $M$ & $S D$ & $M$ & $S D$ \\
\hline Self-perceptions & .75 & 6.46 & 0.72 & 6.84 & 0.66 & .78 & 6.53 & 0.75 & 6.86 & 0.77 & .79 & 6.53 & 0.83 & 6.78 & 0.68 \\
\hline Perception of partner & .83 & 6.80 & 0.85 & 7.11 & 0.83 & .85 & 6.83 & 0.85 & 7.24 & 0.88 & .85 & 6.84 & 0.90 & 7.06 & 0.90 \\
\hline Perception of the ideal partner & .74 & 7.44 & 0.52 & 7.77 & 0.49 & .76 & 7.50 & 0.59 & 7.80 & 0.47 & .74 & 7.51 & 0.62 & 7.78 & 0.52 \\
\hline Perception of the typical partner & .88 & 5.92 & 0.89 & 5.98 & 0.81 & - & - & - & - & - & .87 & 6.10 & 0.91 & 6.04 & 0.84 \\
\hline Self-esteem & .86 & 3.38 & 0.41 & 3.25 & 0.47 & - & - & - & - & - & - & - & - & - & - \\
\hline Satisfaction & .87 & 7.75 & 1.28 & 8.01 & 1.13 & .92 & 7.85 & 1.27 & 8.10 & 1.15 & .93 & 7.75 & 1.20 & 7.88 & 1.65 \\
\hline Ambivalence & .84 & 2.62 & 1.76 & 2.02 & 1.54 & .90 & 2.51 & 1.80 & 1.75 & 1.15 & .91 & 2.25 & 1.56 & 2.00 & 1.84 \\
\hline Conflict-negativity & .72 & 2.84 & 1.35 & 2.90 & 1.47 & .77 & 2.90 & 1.47 & 2.99 & 1.46 & .78 & 2.93 & 1.14 & 2.92 & 1.52 \\
\hline Constructive-destructive style & .91 & 3.48 & 1.13 & 3.44 & 1.31 & .86 & 3.82 & 1.41 & 3.71 & 1.47 & .85 & 3.88 & 1.34 & 3.64 & 1.42 \\
\hline
\end{tabular}

The "reality" paths (e.g., $\beta_{1}$ ) tap actors' understanding of their partners' qualities (i.e., what they see in their partners that their partners also see in themselves). Misunderstandings or illusions refer to actors' idiosyncratic perceptions (i.e., what they see in their partners that their partners do not see in themselves). This residualized measure of illusion is obtained by partialing the effects of the partner's reality out of the actor's perceptions (i.e., by controlling for the actor's understanding of the partner's self-image). The "projection" paths (e.g., $\beta_{2}, \beta_{3}$ ) index whether actors' self-images or ideals shape the nature of these illusions or motivated misunderstandings.

Building on these equations, Figure 1 presents our basic model of positive illusions in romantic relationships (see Murray et al., 1996). The double-arrowed line connecting men's and women's self-views taps similarity between partners' selfperceptions. Paths a through e index the links between models of self and models of others. Nonprimed paths (e.g., a) lead to women's criterion variables, whereas primed paths (e.g., $\left.\mathbf{a}^{\prime}\right)$ lead to men's criterion variables. Paths $\mathbf{a}$ and $\mathbf{a}^{\prime}$ tap whether intimates' ideals reflect their own self-images. Paths $\mathbf{b}$ and $\mathbf{b}^{\prime}$ tap whether ideals are also attuned to the "reality" of their partners' self-perceptions. Paths e and e' represent "social reality" or convergence effects, tapping the link between people's representations of their partners and their partners' self-perceptions. Paths $\mathbf{c}$ and $\mathbf{c}^{\prime}$ index projection, assessing whether individuals see themselves in their partners. And finally, paths $\mathbf{d}$ and $\mathbf{d}^{\prime}$ index intimates' tendency to see partners through the filters provided by their ideals or essentially to see them, not as they are, but as they wish to see them.

Paths $f$ through $j$ index the links between models of self and other and relationship well-being. Paths $i$ and $i$ index social reality effects, linking partners' actual attributes to actors' satisfaction. Paths $f$ and $f^{\prime}$ index the direct links between actors' self-images and satisfaction. The ideal paths $\mathbf{g}$ and $g^{\prime}$ index the direct effects of ideals on satisfaction. The projected illusions paths $h$ and $h^{\prime}$ index the extent to which idealizing a partner

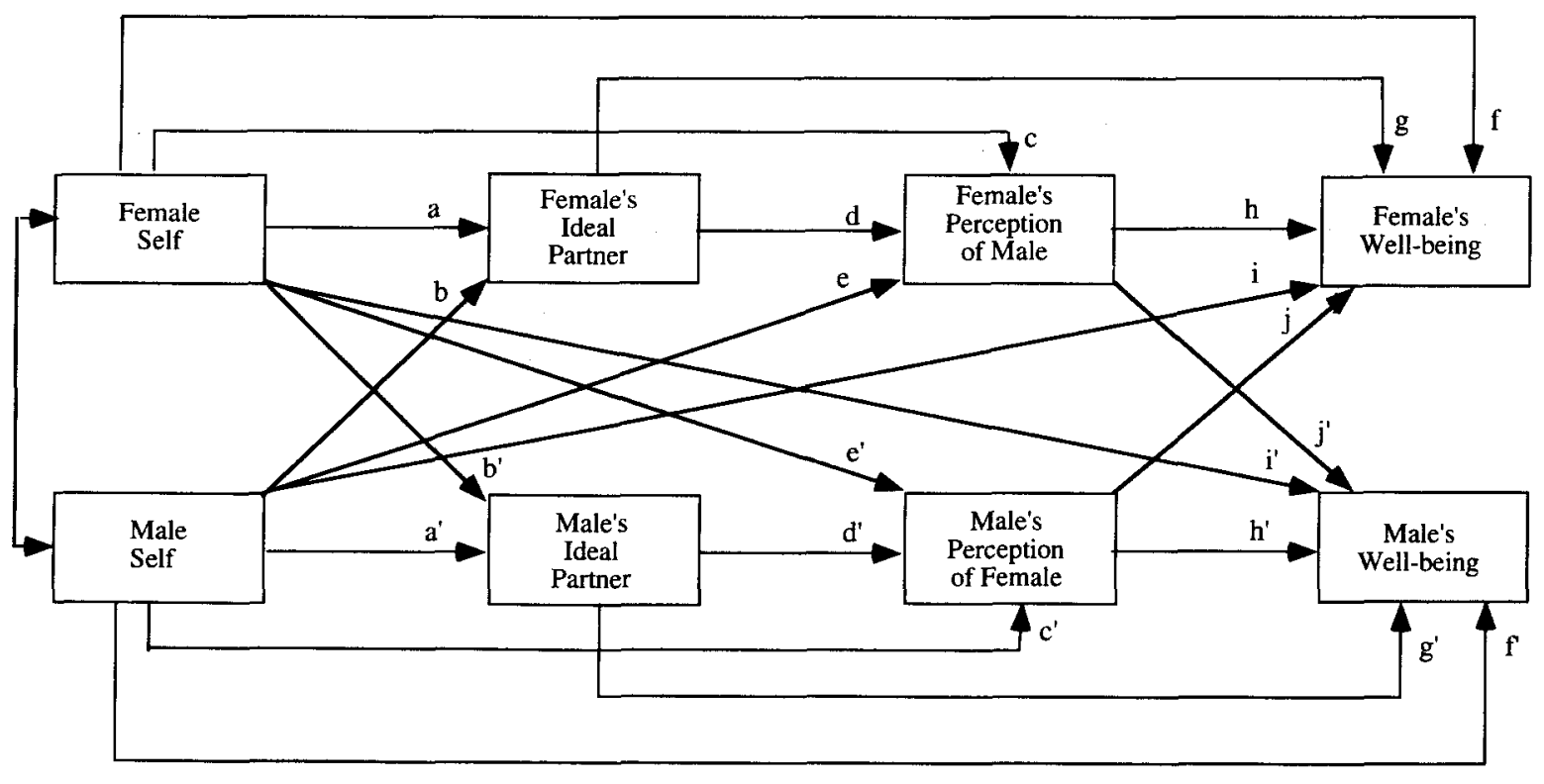

Figure 1. Positive illusions and well-being. 
predicts actors' satisfaction. The reflected illusions paths $\mathbf{j}$ and $j$ ' index the effects of being idealized on partners' satisfaction. Estimates for the residual correlations between pairs of men's and women's variables (e.g., ideals) were also included in the estimation of this model and all future models, although for simplicity, they are not included in the figure. ${ }^{2}$

Each path in this model represents a partial or unique effect. For example, path c represents one possible source of the woman's construction or illusion-how much she tends to see herself in her partner, with the reality of his actual or self-perceived attributes (path e) held constant. Path i represents the direct effect of the man's "reality" on the woman's satisfaction, controlling for any degree of reality matching (path e). That is, do the qualities that men see in themselves-but women fail to see in them-relate to women's satisfaction? The direct ideal path $\mathrm{g}$ taps whether the qualities that women desire-but fail to see in their partners-predict their satisfaction. And the projected illusions paths $\mathbf{h}$ and $\mathbf{h}^{\prime}$ index whether actors' illusions or misunderstandings predict their satisfaction, controlling for their actual understanding of their "real" partners (paths $\mathbf{e}$ and $\mathbf{e}^{\prime}$ ).

To test this (and all subsequent) models, we used the structural equation modeling program within the CALIS (Covariance Analysis of Linear Structural Equations) procedure of SAS. Because of its ability to test the fit of competing models, structural equation modeling allows us to test for gender differences in our path models by constraining certain paths to be equal (Kenny, 1996). For example, we could test whether men and women are equally attuned to the reality of their partners' attributes. We would do this simply by comparing the fit of a model that estimates common "reality" coefficients for men and women (equality constraints placed on paths $e$ and $e^{\prime}$ ) to the fit of a model that estimates separate "reality" coefficients (paths $e$ and $e^{\prime}$ free to vary). If men and women did differ in their accuracy or understanding, the goodness of fit for the model estimating separate reality coefficients would be significantly better (i.e., a smaller chi-square) than the goodness of fit for the model estimating common reality coefficients (a 1-df test).

As a general analytic strategy, we first fit models estimating separate path coefficients for men and women. For example, we allowed the projection and reality paths predicting men's and women's impressions to differ. In most cases, the size of the paths was similar for both genders. So we then fit models estimating pooled (i.e., common) path coefficients for men and women (i.e., we placed equality constraints on corresponding men's and women's paths). In reporting our results, we present the pooled estimates for the path coefficients, unless the previously mentioned model test revealed significant gender differences. When men and women differ, we present separate estimates for the paths. We present separate path coefficients for men and women only when the reduction in chi-square is at least marginally significant $(p<.10)$. In such cases, we present the difference in chi-square when we note the gender difference in the text. ${ }^{3,4}$

\section{A Concurrent Look: Idealization, Understanding, and Well-Being}

Table 2 presents pooled, standardized path coefficients for the positive illusions model at each time period. To facilitate read- ing the tables, we placed the labels for each path in bold in the leftmost column of the table. First, the similarity between partners' self-images was minimal, $r(119)=.11$. Models of the ideal partner were strongly tied to intimates' self-perceptions: The better, or more positively, individuals felt about themselves, the higher their hopes for the ideal partner, as the significant pooled self-projection paths $\mathbf{a}$ and $\mathbf{a}^{\prime}$ indicate. The partner's actual qualities also played a (limited) role in shaping these standards: Intimates set higher standards when partners had higher selfregard, as the significant pooled reality paths $\mathbf{b}$ and $\mathbf{b}^{\prime}$ illustrate.

At Time 1, intimates' impressions of their partners reflected a mixture of reality and illusion, and this continued to be true as time passed. Impressions partly mirrored the partner's actual attributes, as the significant social reality paths $\mathbf{e}$ and $\mathbf{e}^{\prime}$ illustrate. But importantly, the projection of self-images and images of the ideal partner predicted the nature of actors' illusions, as the significant self and ideal projection paths ( $c$ and $c^{\prime}$ and $\mathbf{d}$ and $\left.d^{\prime}\right)$ illustrate. Intimates with higher self-regard and rosier, more rigorous ideals held more idealized impressions of their part-

\footnotetext{
${ }^{2}$ As in our previous study (Murray et al., 1996), we constrained the crossover paths from women's ideals to men's perceptions and well-being to be zero and vice versa, because these paths were of little practical or theoretical importance. Doing so did not weaken the fit of any of the models.

${ }^{3}$ In all cases, the chi-square for the fit of the models with our imposed constraints did not significantly differ from the chi-square for the fit of models free of these constraints.

${ }^{4}$ At this point, the reader might be entertaining some questions about our use of $S E M$ over ordinary least squares (OLS) regression. SEM conveys several important advantages over the use of OLS regression, especially in the analysis of nonindependent or couple data (Kenny, 1996). SEM s first advantage is its full information approach. SEM allows us to provide simultaneous tests of sets of hypotheses, whereas OLS regression tests hypotheses in isolation. SEM also allows us to combine the information from both members of each couple and test whether pooling across gender is statistically appropriate. In the absence of sex differences, $S E M$ provides both more efficient and statistically more powerful tests of the parameters relative to OLS regression. SEM also allows us to apply other constraints to a model (e.g., constraining the ideal crossover paths to zero) and test whether these constraints are reasonable (using chi-square tests). SEM does have potential limitations. First, constructing structural models necessitates specifying causal links among the variables in the model, as Figure 1 illustrates. However, these causal paths are only hypothetical (despite the illusion of causality that drawing arrows creates). Models with different causal structures would fit the data just as well. The cross-sectional data can only index the magnitude of the hypothesized paths, not the causal implications. Only the longitudinal data can offer limited insight into the ultimate truth of these causal pathways. Low sample sizes can also limit the use of SEM. Against some apparent standards our sample size could be considered somewhat low (although our original sample of 121 is one of the largest in the literature). With lower $N \mathrm{~s}$, the power of the chisquare tests is reasonably low, although the goodness-of-fit statistics are less affected by sample size (e.g., Bentler, 1990). For this reason, we treat gender differences as reliable if the difference in chi-square between nested models is marginally significant $(p<.10)$. More generally, it is important to realize that fit statistics do not indicate whether a given model is correct, only that it is not obviously incorrect. We are not using $S E M$ to prove the fit of a model or to determine causality. $S E M$ is only a tool that can estimate parameters of a specified causal model, but the appropriateness of the model is primarily a theoretical, not a statistical, question.
} 
Table 2

Positive Illusions and Satisfaction at Times 1, 2, and 3: Pooled, Standardized Path Coefficients

\begin{tabular}{|c|c|c|c|}
\hline Path & Time 1 & Time 2 & Time 3 \\
\hline \multicolumn{4}{|c|}{ Predicting actor's ideal partner } \\
\hline $\begin{array}{l}\mathbf{b} \text { and } \mathbf{b}^{\prime} \text { : Reflection of partner's self-image } \\
\mathbf{a} \text { and } \mathbf{a}^{\prime} \text { : Projection of actor's self-image }\end{array}$ & $\begin{array}{l}.161^{* * * *} \\
.531^{* * *}\end{array}$ & $\begin{array}{l}.161^{* *} \\
.499^{* * *}\end{array}$ & $\begin{array}{l}.290^{* * *} \\
.546^{* * *}\end{array}$ \\
\hline \multicolumn{4}{|c|}{ Predicting actor's perceptions of partner } \\
\hline $\begin{array}{l}\text { e and } e^{\prime}: \text { Reflection of partner's self-image } \\
c \text { and } c^{\prime}: \text { Projection of actor's self-image } \\
d \text { and } d^{\prime} \text { : Projection of actor's ideals }\end{array}$ & $\begin{array}{l}.193^{* * * *} \\
.266^{* * * *} \\
.335^{* * * *}\end{array}$ & $\begin{array}{l}.130^{* *} \\
.249^{* * *} \\
.430^{* * *}\end{array}$ & $\begin{array}{l}.253^{* *} \\
.161^{*} \\
.429^{* * *}\end{array}$ \\
\hline \multicolumn{4}{|c|}{ Predicting actor's satisfaction } \\
\hline $\begin{array}{l}\text { i and } i^{\prime}: \text { Partner's self-image } \\
f \text { and } \mathbf{f}^{\prime}: \text { Actor's self-image } \\
\text { g and } \mathbf{g}^{\prime}: \text { Actor's ideals } \\
\mathbf{h} \text { and } \mathbf{h}^{\prime}: \text { Projected illusions } \\
\mathbf{j} \text { and } \mathbf{j}^{\prime}: \text { Reflected illusions }\end{array}$ & $\begin{array}{l}-.176^{* * *} \\
-.049 \\
.020 \\
.612^{* * *} \\
.247^{* * *}\end{array}$ & $\begin{array}{l}-.024 \\
-.089 \\
-.111 \\
.797^{* * * *} \\
.154^{* *}\end{array}$ & $\begin{array}{l}-.053 \\
-.032 \\
-.069 \\
.617^{* * *} \\
.189^{* *}\end{array}$ \\
\hline
\end{tabular}

ners. Conversely, intimates with weaker self-regard and less rigorous ideals were less generous in their (illusory) depictions of their partners' attributes. ${ }^{5}$

Most critical, and further replicating our previous work (Murray et al., 1996), intimates were happier in their relationships when they idealized their partners, as the significant pooled projected illusion paths $h$ and $h^{\prime}$ illustrate. The more positive, or the more idealized, their constructions-controlling for their partners' actual attributes-the happier actors were in their relationships. Being idealized also predicted greater satisfaction. That is, intimates were happier in their relationships when their partners looked beyond their actual attributes and saw the best in them, as the significant pooled reflected illusion paths $\mathbf{j}$ and $\mathbf{j}^{\prime}$ illustrate. None of the direct effects of ideals (paths $\mathbf{g}$ and $\mathbf{g}^{\prime}$ ) were significant, suggesting that falling short of a partner's ideals need not detract from satisfaction concurrently. Also, none of the direct effects of actors' self-images on their own well-being were significant (paths $f$ and $f^{\prime}$ ). Only one effect for the partner's reality (paths $i$ and $i^{\prime}$ ) emerged. At Time 1 , actors were less happy when their partners claimed virtues in themselves that the actors failed to see in them.

Warding off difficulties? If idealization predicts greater satisfaction partly because of its role in warding off difficulties and doubt, intimates should also experience less concurrent conflict and less ambivalence when they idealize their partners and their partners idealize them. The results of these analyses are presented in the Appendix and we simply summarize them here. Idealizing a partner (paths $h$ and $h^{\prime}$ ) and being idealized (paths $\mathbf{j}$ and $\mathbf{j}^{\prime}$ ) consistently predicted less frequent and less destructive conflicts and less ambivalence, as the significant projected and reflected illusions paths illustrate. It is important to note that idealizing and being idealized continued to predict fewer, less destructive conflicts and less doubt even when we controlled for satisfaction.
Isolated social reality effects also emerged. Actors reported less frequent and less destructive conflicts and less ambivalence the more positive their self-perceptions (paths $f$ and $f^{\prime}$ ). Actors also reported more ambivalence and more conflict when their partners claimed virtues in themselves that actors failed to see in them (paths $\mathbf{i}$ and $\mathbf{i}^{\prime}$ ). Glimmers of evidence suggested that unfulfilled ideals may sometimes function as standards. Men and women generally reported more destructive conflicts the more their partners fell short of their ideals (paths $\mathbf{g}$ and $\mathbf{g}^{\prime}$ ).

Understanding and well-being: A global test. Although perfectly suited for examining the effects of idiosyncratic (or illusory) perceptions, the positive illusions model presented in Figure 1 is imperfectly suited for examining the effects of shared perceptions (e.g., women's accurate understanding of men's self-perceptions). To examine the effects of understanding, we employed the strategy used by Swann et al. $(1992,1994)$. We obtained pooled estimates for structural models predicting men's and women's satisfaction from men's and women's impressions of their partners, their own self-images, and the "understanding" interaction terms (i.e., men's understanding of

\footnotetext{
${ }^{5}$ As a further testament to the idealized nature of these perceptions, a 2 (self vs. partner) by 2 (male vs. female) within-subjects analysis of variance revealed that intimates saw their partners in a more positive light (on average) than their partners saw themselves. (This main effect was significant at each time interval.) At Time 1, for example, partner evaluations ( $M=6.96)$ were more favorable than self-evaluations ( $M$ $=6.65), F(1,120)=42.27, p<.001$, although this effect was strongest for women. Dating men's ratings did not exceed their partners' selfratings in their depictions. However, this anomaly disappeared over time. At Time 3, dating men saw their partners in a more positive light than women saw themselves. As further evidence of idealization or distortion, intimates also saw their own partners $(M=6.96)$ in a more favorable light than they saw the typical partner $(M=5.95), F(1,120)$ $=198.30, p<.001$, at Time 1 and as time passed.
} 
women's self-perceptions and women's understanding of men's self-perceptions). These interaction terms allow us to tap the effects of understanding a partner as well as the effects of being understood by a romantic partner. ${ }^{6}$

As they should, the results for the pooled main effects parallel those presented in Table 2. Despite the predictions of self-verification theory, being understood by an intimate partner did not predict satisfaction at any of the time periods, $t \mathrm{~s}<1$. Nor did understanding a partner predict intimates' own satisfaction at Times 1 or 2 , $t \mathrm{~s}<1$. At Time 3 , however, women were least happy when they more accurately understood their partners' self-doubts (coefficient $=-.183, p<.05$ ), although the same was not true for men. The difference in chi-square for the models estimating separate and pooled understanding coefficients was marginally significant, $\chi^{2}(1, N=58)=3.61, p<.10$. Thus, despite the passage of time, intimates were consistently happier when they idealized one another, not when they were more accurately understood.

Trait-specific understandings. The preceding analyses derive indices of understanding and misunderstanding from the mean positivity of perceptions. Even though these analyses suggest that understanding a partner's global self-regard has little bearing on happiness, understanding a partner's particular selfschema or personality profile could still predict well-being (e.g., Kobak \& Hazan, 1991). This reflects the fact that such withincouple correlations provide idiographic measures of agreement that are independent of overall positivity but capture whether intimates agree in terms of their relative ratings of specific traits (i.e., their personality profiles). In these terms, Bill might be happier if he sees himself as more warm than critical and Hillary shares this perception, regardless of how positively or negatively Hillary sees Bill.

We computed such a set of trait-specific understanding correlations by computing the intracouple correlation between the actor's ratings of the partner on each trait and the partner's selfratings on each trait. At Time 1, the correlations tapping women's understanding of men's self-perceptions on the Interpersonal Qualities Scale ranged from -.47 to $.89(M=.34 ; S D$ $=.26$ ), and the correlations tapping men's understanding of women's self-perceptions ranged from -.15 to $.81(M=.40 ; S D$ $=.24$ ). Parallel ranges and means emerged at Times 2 and 3. At Time 1, men's understanding of women did not predict their own, $r(119)=.15$, or their partners' $r(119)=.10$, happiness. Identical results emerged for women's understanding of men: $r(119)=.08$ and $r(119)=.04$, respectively. ${ }^{7}$

At Time 2, however, women and men were happier the greater the woman's understanding of the man's self-image, $r(71)=$ $.25, p<.05$ and $r(71)=.29, p<.05$. Also, women were happier the more their partners understood them, $r(71)=.23, p<.05$, although understanding their partners' self-images did not make men any happier, $r(71)=.12$. At Time 3 , women and men were still happier the more the woman understood the man's self-schema, $r(56)=.32, p<.05$ and $r(56)=.35, p<$ .05 , although men's understanding did not make men or women any happier, $r(56)=.04$ and $r(56)=-.11$, respectively. The fact that these correlations were not apparent at Time 1 for only those couples still together at Times 2 and 3 at least suggests that understanding a partner's actual self-schemas becomes more important for satisfaction as time passes.

Trait-specific idealization. We used a similar approach to examine the effects of trait-specific illusions or hope-driven misunderstandings. To do this, we first calculated two idealization correlations per couple - the man's ideal for each trait with his perception of his partner on that trait, and the woman's ideal for each trait with her perception of her partner on each trait. These correlations tap the degree to which ideals structure intimates' perceptions of the relative descriptiveness of their partners' traits, although they are independent of the positivity of these ratings. These correlations ranged from -.12 to .95 ( $M=$ $.56 ; S D=.25)$ for women and from -.50 to $.96(M=.44 ; S D$ $=.32$ ) for men. Parallel ranges and means emerged at Times 2 and 3. We then correlated these idealization indices with satisfaction, after partialing out the trait-specific understanding correlation between the actor's perception of the partner and the partner's self-perception. The resulting correlations represent the pure illusions correlation: that between ideals and perceptions with the actor's actual understanding of the partner's reality held constant.

Men and women were consistently happier the greater the convergence between their ideal prototypes and constructions of their partners. Initially, these projected illusions correlations were as follows: $r(119)=.42, p<.001$ for men and $r(119)=$ $.38, p<.001$ for women. At Time 2 , they were $r(71)=.36, p<$ .01 for men and $r(71)=.32, p<.01$ for women, and at Time 3 they were $r(56)=.45, p<.01$ for men and $r(56)=.44, p<.01$ for women. Also, individuals ( particularly women) were consistently happier the more their partners idealized their status on specific attributes. These reflected illusions correlations were as follows: at Time $1, r(119)=.22, p<.05$ for men and $r(119)=$ $.24, p<.05$ for women; at Time $2, r(71)=.12, n s$ for men and $r(71)=.20, p<.09$ for women; and at Time $3, r(56)=.19$, $n s$ for men and $r(56)=.21, p<.10$ for women. In summary, idealizing a partner and being idealized-on a trait-specific basis-predicted greater satisfaction, just as idealizing a partner on a global basis enhanced well-being.

\section{Accommodations to Reality? A Summary}

Even as these relationships progressed, intimates' impressions of their partners were still largely constructions, reflecting the projection of self-images and ideals. And idealizing a part-

\footnotetext{
${ }^{6}$ To understand the meaning of the cross-product term, imagine that we have first centered the two independent variables, partner self-ratings and actor's perceptions, by subtracting the relevant mean from each observation. Now the meaning of the cross-product terms is clear. If both perceptions are positive (above the relevant mean), the actor understands the partner, yielding a positive cross product. Similarly, if both perceptions are negative (below the relevant mean), the actor also understands the partner, again yielding a positive cross product. However, if one perception is positive and the other is negative, then a misunderstanding occurs, yielding a negative cross product. Self-verification implies that understanding will lead to satisfaction and misunderstandings to dissatisfaction. Therefore, if self-verification relates to satisfaction in this manner, we should find a significant positive coefficient for the cross-product term. Of course, the crucial difference between this theory and the present model is in the case where an actor understands (i.e., agrees with) a partner's negative self-perceptions.

${ }^{7}$ We transformed the reported intracouple correlations using Fisher's recommended procedure and then correlated these indices with satisfaction. Transforming the correlations did not change any of the results.
} 


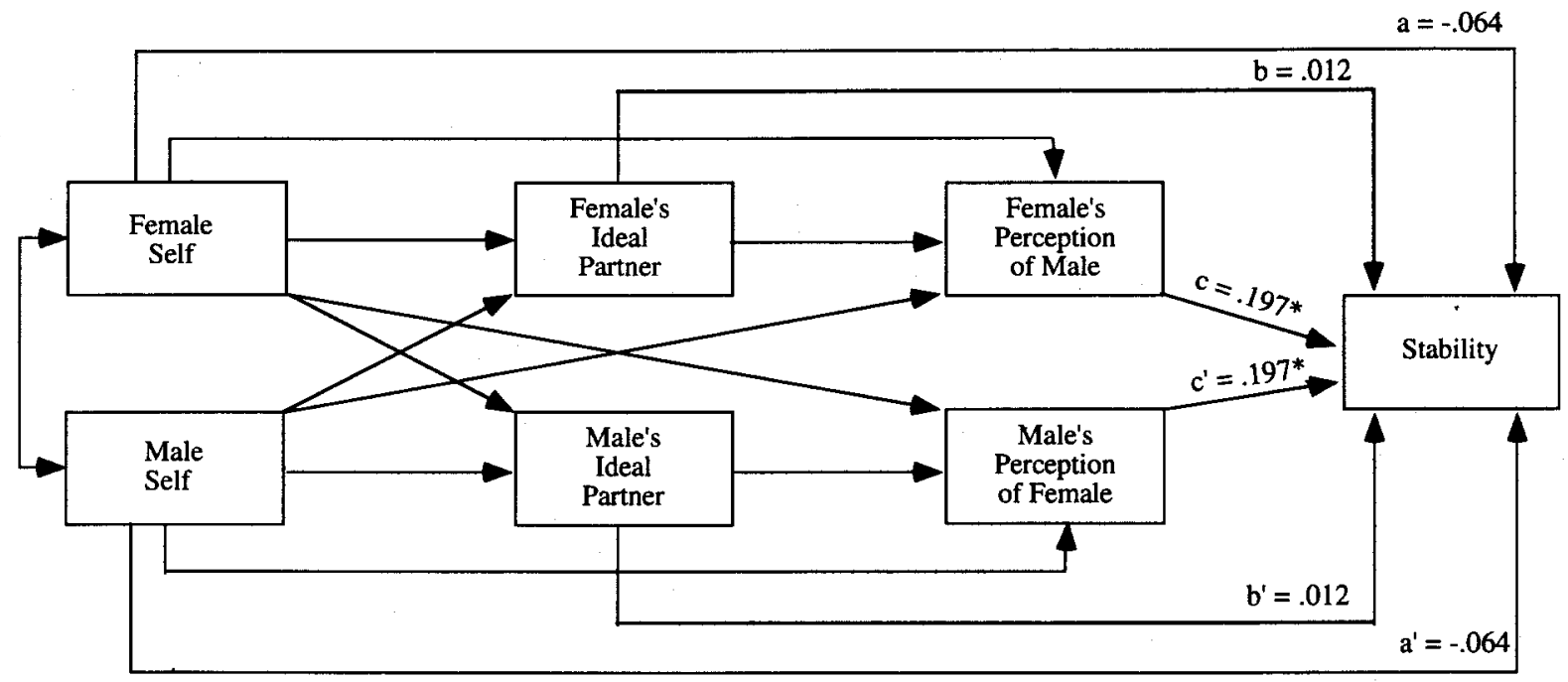

Figure 2. Positive illusions and stability. Goodness-of-fit index $=.99$, comparative fit index $=1.0, \chi^{2}(10$, $N=115)=5.35, n s .{ }^{*} p<.05$.

ner and being idealized predicted greater satisfaction, fewer conflicts, and less serious doubts. However, intimates did also respond to sterner realities. For instance, perceptions that a partner fell short of an individual's ideals predicted more destructive conflict styles. Women were also happier the better they understood their partners' qualities at a trait-specific level for the first time at 4 months and again at 12 months. At both time points, men were happier the better women understood their self-schemas. However, women were least happy at Time 3 when they actually understood the global (and fallible) nature of their partners' self-regard.

\section{The Dissolution of Dating Relationships}

The results thus far suggest that intimates remain surprisingly immune to "reality" as time passes. Do such idealized, perhaps myopic, perceptions also ward off dissolution, as we hypothesized, perhaps by buffering intimates against the harmful effects of doubt and conflict? Or does idealization leave intimates vulnerable to breakup, even though it provides a (selfdeceptive) sense of security in the present? Does more accurately understanding a partner's qualities, then, ultimately prove critical for establishing lasting security and stability?

Figure 2 presents the model linking initial idealization to relationship stability at the year's end $(1=$ together; $0=$ apart $)$. Paths $\mathbf{a}$ and $\mathbf{a}^{\prime}$ index social reality effects, tapping whether intimates' actual attributes had any bearing on relationship stability. Paths $b$ and $b^{\prime}$ index the direct effects of individuals' ideals in predicting stability. Positive illusion paths $\mathbf{c}$ and $\mathbf{c}^{\prime}$ tap whether positive illusions predict stability. Again, estimates for the residual correlations between pairs of men's and women's variables (e.g., ideals) were also included in the estimation of the model, although they are not in the figure. Each path in this model reflects a partial or unique effect. For example, paths b and $\mathbf{b}^{\prime}$ tap the effects of unfulfilled ideals on stability-that is, whether the qualities intimates desire but fail to see in their partners predict dissolution.

Figure 2 also contains the pooled, standardized path coeff- cients testing the long-term repercussions of idealization. All paths (labeled and unlabeled) were included in the estimation of the model. We report only the path coefficients predicting stability because the remaining ( unlabeled) coefficients parallel those presented in Table $3 .^{8}$ As Figure 2 illustrates, individuals' "real" or self-perceived qualities (paths a and $\mathbf{a}^{\prime}$ ) did not predict stability. Also, falling short of a partner's ideals (paths $\mathbf{b}$ and $\mathbf{b}$ ') did not predict stability. However, the pooled positive illusions paths $\mathbf{c}$ and $\mathbf{c}^{\prime}$ were significant and positive, suggesting that idealization can have self-fulfilling rather than self-defeating effects. As we hypothesized, relationships were more likely to persist the more intimates idealized one another. These effects are also mirrored in the mean comparisons of stayers' and leavers' perceptions in Table 3.

A mediation model? Our original model suggests that satisfaction should mediate the link between positive illusions and stability. That is, idealization might promote stability by virtue of its beneficial effects on satisfaction ( see Figure 1). If this is the case, satisfaction (the more inclusive variable) should predict stability above and beyond the influence of illusions. And second, the relation between illusions and stability should approach zero when satisfaction is included in the model if satisfaction completely mediates the illusions-stability relation.

An analysis of this expanded model indeed indicated that feelings of satisfaction completely mediated the link between positive illusions and stability. The more satisfied intimates were initially, the less likely they were to break up. And once satisfaction was controlled, the pooled positive illusions paths were no longer significant. With these results in hand, a cynic might conclude that idealization has little unique predictive ability, but further analyses will reveal that positive illusions do

\footnotetext{
${ }^{8}$ We follow this same strategy (i.e., presenting only the coefficients for the "new" paths) in subsequent models. Despite the reduction in $N$ in the longitudinal analyses, the evidence for the basic components of the positive illusions model (see Table 3 and the Appendix) remains strong.
} 
Table 3

Time 1 Perceptions and Feelings for Intimates Involved in Stable Versus Unstable Relationships

\begin{tabular}{lccc}
\hline \multicolumn{1}{c}{ Variable } & $\begin{array}{c}\text { Stayers } \\
(N=58)\end{array}$ & $\begin{array}{c}\text { Leavers } \\
(N=43)\end{array}$ & $t$ \\
\hline Female self & 6.83 & 6.77 & $n s$ \\
Male self & 6.53 & 6.40 & $n s$ \\
Female's ideal partner & 7.83 & 7.72 & $n s$ \\
Male's ideal partner & 7.50 & 7.36 & $n s$ \\
Female's typical partner & 6.02 & 5.91 & $n s$ \\
Male's typical partner & 6.03 & 5.69 & $2.01^{* *}$ \\
Female's view of partner & 7.25 & 6.85 & $2.30^{* *}$ \\
Male's view of partner & 6.94 & 6.60 & $1.90^{*}$ \\
Female satisfaction & 8.32 & 7.48 & $3.59^{* * *}$ \\
Male satisfaction & 8.13 & 7.21 & $3.45^{* * * *}$ \\
Female conflict & 2.67 & 3.33 & $-2.31^{* *}$ \\
Male conflict & 2.67 & 3.22 & $-2.00^{* *}$ \\
Female ambivalence & 1.76 & 2.65 & $-2.66^{* * *}$ \\
Male ambivalence & 2.14 & 3.17 & $-2.79^{* * *}$ \\
Female destructive style & 3.31 & 3.76 & $-1.78^{*}$ \\
Male destructive style & 3.32 & 3.79 & $-2.08^{* *}$ \\
\hline
\end{tabular}

${ }^{*} p<.10 .{ }^{* *} p<.05 . \quad{ }^{* * *} p<.01$.

have self-fulfilling effects on breakups (and later well-being) that are not already encompassed by satisfaction.

Buffering doubts or accentuating concerns? Certain sterner realities did catch up with intimates over time. Individuals in unstable relationships reported more conflicts, destructive conflict styles, and ambivalence at Time 1 than did individuals in stable relationships ( see Table 3 ). We had predicted that idealizing a partner would ward off dissolution partly because it would lessen (rather than accentuate) the harmful effects of such conflicts and doubts.

To explore this buffering hypothesis, we obtained pooled estimates for a structural model predicting stability from men's and women's positive illusions, initial reports of negativity, and the cross-product interaction terms. ${ }^{9}$ If idealization moderates or buffers the deleterious effects of negativity, we should find a significant interaction (i.e., the slope of the line predicting breakup from negativity will differ when men's or women's perceptions are more or less idealized).

Table 4 presents the pooled, standardized coefficients testing the buffering hypothesis for men and women. The significant main effects of negativity illustrate that more serious initial doubts, as indexed by greater reports of conflicts, destructive-

Table 4

Positive Illusions, Negativity, Buffering, and Stability: Standardized Path Coefficients

\begin{tabular}{lc}
\hline \multicolumn{1}{c}{ Term } & Stability \\
\hline Men's and women's positive illusions & .040 \\
Men's and women's reports of negativity & $-.142^{* * *}$ \\
Men's buffering interaction term & $.205^{* *}$ \\
Women's buffering interaction term & .018 \\
\hline
\end{tabular}

Note. Goodness-of-fit index $=.99$, comparative fit index $=1.0, \chi^{2}(3$, $N=115)=0.33, n s$.

$* * p<.05$. ${ }^{* * *} p<.01$.

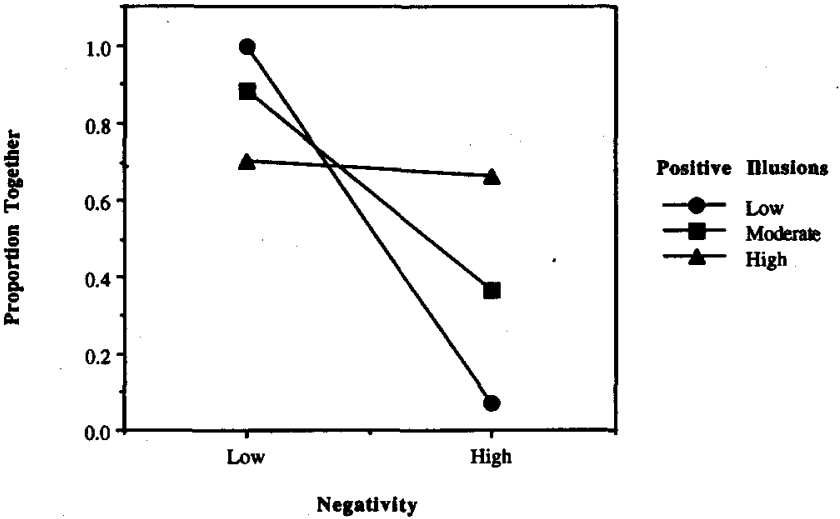

Figure 3. The buffering effect of men's illusions in predicting stability.

ness, and ambivalence, did predict more frequent breakups. However, the relation between negativity and dissolution differed depending on the strength of men's, but not women's, illusions, as the significant buffering interaction term for men illustrates. The difference in chi-square for the models estimating separate and pooled buffering coefficients was marginally significant, $\chi^{2}(1, N=115)=2.78, p<.10$.

To illustrate how idealization attenuated the harmful effects of negativity, we computed regression equations predicting stability from negativity for men with low, average, and high illusions. Low and high illusions were defined as one standard deviation below and above the mean, respectively. Figure 3 depicts the resulting slopes. Frequent and destructive conflicts and ambivalence predicted more frequent breakups for men low on illusions, but this relation was attenuated when men possessed moderately strong illusions, and it actually disappeared when men idealized their partners the most. As we hypothesized, idealization appeared to fulfill a buffering or compensatory function in these relationships. Couples stayed together-even in the face of reasons to doubt-if men's illusions were sufficiently strong. And it is critical that idealization buffered the impact of negativity for men even when we controlled for their Time 1 satisfaction. Such interpersonal generosity seems to function as a compensatory force in developing relationships, extending a protective influence that is not shared by more amorphous feelings of satisfaction.

Mutual understanding and stability. The results of the path models suggest that directional misunderstandings-in the form of positive illusions-predicted greater stability. To examine the link between understanding and stability, we obtained pooled estimates for models predicting stability from men's and women's images of their partners, their self-images, and the understanding interaction terms. The results for the pooled main effects parallel those presented in Figure 1. Understanding a partner (i.e., self-verification) did not predict longevity, $t<1$.

\footnotetext{
${ }^{9}$ The positive illusions term was the actor's perception of the partner (Time 1), residualized on the partner's self-perceptions. The negativity composite was based on an equal weighting of conflict, destructiveness, and ambivalence scores (Time 1). We centered all variables (using $z$ scores) to minimize collinearity.
} 
Romances were simply more likely to persist the more intimates idealized one another initially.

Trait-specific (mis) understandings and stability. A self-verification perspective might also suggest that relationships are more likely to last if, for example, Hillary sees herself as more responsive than critical and Bill shares this perception, than if Bill has little understanding of Hillary's self-schema. To examine this question, we conducted a regression analysis predicting stability from the within-couple understanding correlations. Neither women's understanding of men, $\beta=.057$, nor men's understanding of women, $\beta=.088$, predicted breakup. However, a regression analysis predicting stability from the withincouple illusion correlations revealed that such trait-specific misunderstandings warded off dissolution, as we predicted, $R^{2}$ $=.10, F(2,112)=6.29, p<.01$. Relationships were more likely to persist the greater the convergence between intimates' ideal prototypes and their impressions of their partners when their understanding of their partners' actual self-ratings was held constant: $\beta=.284, t(112)=3.17, p<.01$ for men; $\beta=.152, t(112)$ $=1.70, p<.10$ for women. Further, men's trait-specific illusions predicted greater stability, even when we controlled for their Time 1 satisfaction.

Fulfilling hopes: A summary. Rather than leaving intimates vulnerable to disappointment and, eventually, breakup, idealization actually appeared to play a self-fulfilling function in these developing relationships. As we hypothesized, relationships were more likely to persist the more intimates idealized one another-at both global and trait-specific levels. Idealization even buffered or insulated couples from the deleterious effects of conflicts and ambivalence. Relationships were more likely to persist - even in the face of negativity - when men idealized women the most. When men were less generous in their perceptions, however, relationships tended to dissolve in the face of negativity. Finally, more accurately understanding a partner's "real" qualities did not have any self-fulfilling (or selfdefeating) effects on stability.

\section{Self-Fulfilling or Self-Defeating Prophecies? Changes in Well-Being}

Even for intimates who stayed together, the glow of the romantic experience began to dim somewhat as the year passed. A series of within-couple analyses of variance in which gender and time were the repeated measures revealed that satisfaction did decrease significantly over time (Time $1=8.30$, Time $2=$ 8.15 , Time $3=7.89), F(2,104)=4.53, p<.01$, and that conflicts became more frequent (Time $1=2.61$, Time $2=2.79$, Time $3=2.91), F(2,104)=2.92, p<.06$. Idealizing a partner could have set intimates up for these disappointments, but we predicted that intimates who idealized one another the most would actually be least vulnerable to this malaise. That is, positive illusions might actually act as a transformational force, promoting later satisfaction, decreasing conflicts, and warding off doubts (i.e., the transformation hypothesis).

Figure 4 presents the generic model we used to explore changes in relationship well-being, as reflected in reports of satisfaction, conflict frequency, and destructiveness. Changes in well-being are residualized effects (e.g., variance in Time 2 satisfaction that is not due to Time 1 satisfaction ). Paths $\mathbf{d}$ and $\mathbf{d}^{\prime}$ index stability in satisfaction (or conflict, etc.) as time passes.
Paths e and $\mathbf{e}^{\prime}$ represent social reality effects, tapping whether the "reality" of a partner's attributes catches up with individuals over time, predicting changes in well-being. Paths a and $\mathbf{a}^{\prime}$ tap the link between actors' self-perceptions and later feelings. The ideal paths $\mathbf{b}$ and $\mathbf{b}^{\prime}$ tap how unfulfilled ideals-hoping for more in a partner than one sees-relates to later well-being. The projected illusion paths $\mathbf{c}$ and $\mathbf{c}^{\prime}$ index whether idealizing a partner makes intimates more or less happy as relationships develop. Finally, the reflected illusion paths $f$ and $\mathbf{f}^{\prime}$ index the long-term benefits (or costs) of being idealized.

Changes in satisfaction. Did idealizing a partner actually slow the decline in satisfaction, as we expected? Table 5 presents the pooled standardized path coefficients for the models linking the components of the positive illusions model to changes in satisfaction. ${ }^{10}$ Consistent with our emphasis on the self-fulfilling nature of idealization, women who idealized their partners more at Time 1 were relatively happier in their relationships at year's end (Time 3), as the significant projected illusions effect (path c) illustrates. But idealizing a partner did not predict changes in men's satisfaction (path $\mathbf{c}^{\prime}$ ), $\chi^{2}(1, N=58)=3.17$, $p<.10$. And being idealized (the reflected illusion paths $\mathrm{f}$ and $\left.f^{\prime}\right)$ did not predict changes in satisfaction for men or women.

As we expected, certain social reality effects also emerged. Over the first 4 months, the reality of a partner's attributes crept up on these couples, as evidenced by the marginally significant pooled partner reality paths $\mathbf{e}$ and $\mathbf{e}^{\prime}$. Intimates grew relatively happier at Time 2 the more positive their partners' self-images were at Time 1 . The same effect occurred by Time 3 for women's self-regard (path $\mathbf{e}^{\prime}$ ), but not for men's (path e), $\chi^{2}$ ( $1, N=$ $58)=4.91, p<.05$. A parallel, but marginally significant effect also emerged from Time 2 to Time $3, \chi^{2}(1, N=53)=2.72, p$ $<.10$. In both cases, men's satisfaction grew when their partners' self-images were relatively rosy and suffered when their partners were more self-deprecating. Parenthetically, partner reality effects also emerged when we examined changes in ambivalence, as indexed by the Braiker and Kelley (1979) scale. When their partners were more self-critical at Time 1, both men and women reported growing doubts or uncertainty by Time 3 . The opposite was true when partners had higher self-esteem.

Men's own self-images at Time 1 also predicted changes in their satisfaction by Time 3 , as shown by the significant selfprojection path for men (path $\mathbf{a}^{\prime}$ ) but not for women (path $\mathbf{a}$ ), $\chi^{2}(1, N=58)=4.29, p<.05$. Men with rosier self-images reported relatively more satisfaction, whereas men with weaker self-images suffered greater declines in happiness. Parallel selfprojection effects emerged that predicted both men's and women's Time 2 satisfaction when we used the Time 1 Rosenberg (1965) measure as the index of self-models. Individuals grew relatively happier the higher their self-esteem, whereas individuals with weaker self-esteem suffered relatively greater declines in satisfaction. Overall, each intimate's sense of self-worth became increasingly important for satisfaction as time passed, even though such realities once had little bearing on happiness.

Unfulfilled ideals at Time 1-hoping for more in a partner than one sees-actually predicted relatively greater satisfaction

\footnotetext{
${ }^{10}$ Again, all paths (including the unlabeled paths) were included in the estimation of the model. We present only the paths predicting changes in satisfaction (or conflict, etc.) because the remaining paths mirror those presented in Table 3 and the Appendix.
} 


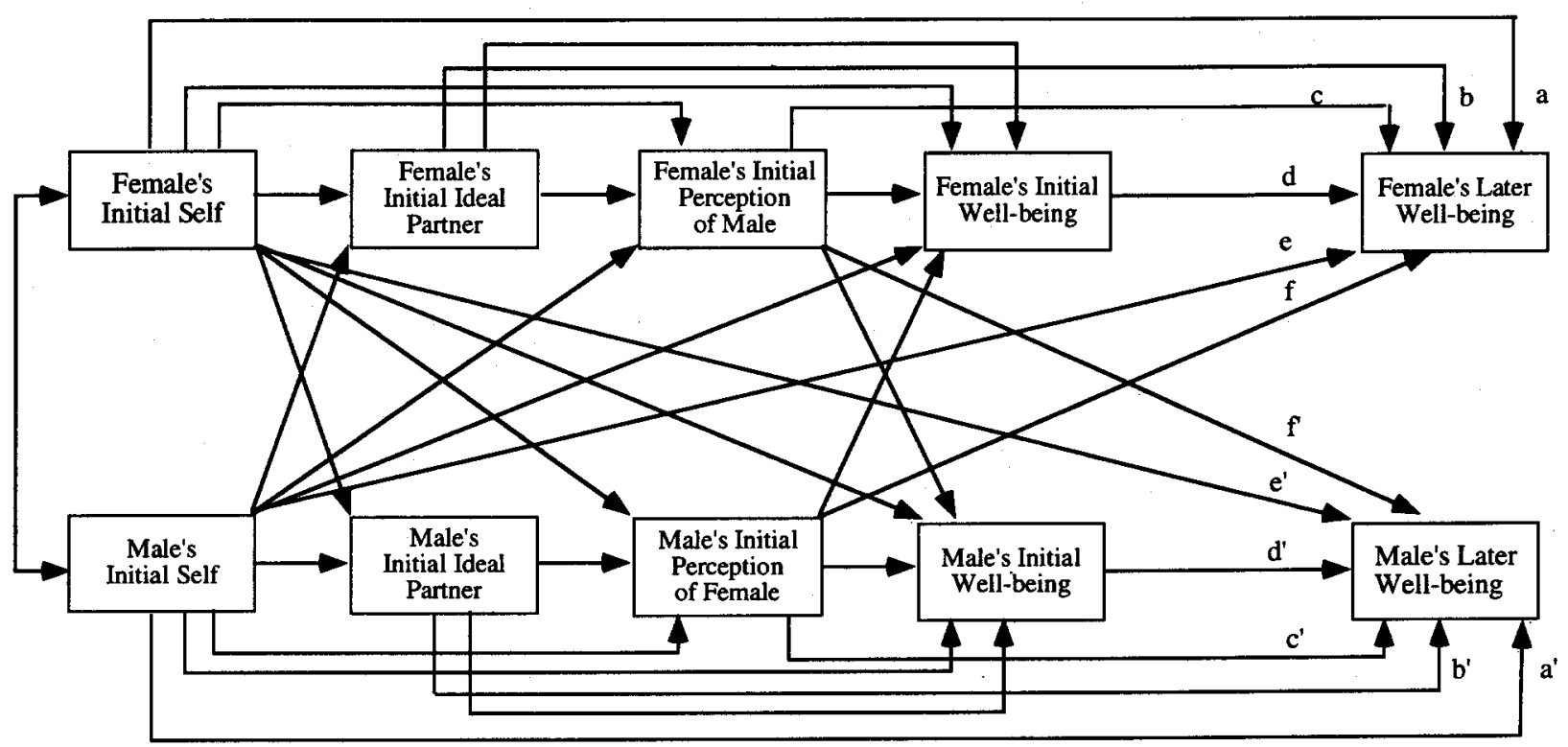

Figure 4. Positive illusions and changes in well-being.

at Time 2 for men (path $\mathbf{b}^{\prime}$ ) but relatively less satisfaction for women (path b), $\chi^{2}(1, N=73)=9.47, p<.05$. For men, even unfulfilled ideals appear to act as filters, leading them to perceive greater reasons for happiness. Women, however, appeared to have greater difficulty keeping the reality of their partners' shortcomings (as compared with their ideals) from dampening satisfaction as time passed.

Changes in conflict and destructiveness. Because of the often hypothesized role of positive illusions in warding off threats (e.g., Taylor \& Brown, 1988), we thought the benefits of positive illusions might surface even more clearly in signs of negativity or distress. That is, idealization might actually slow the increase in conflicts by creating a climate of tolerance or goodwill that defuses conflicts before they arise. Tables 6 and 7 present the pooled path coefficients linking the positive illusions model to later conflicts and destructive conflict styles, respectively.

The benefits of idealizing a partner were indeed realized in less frequent conflicts and less destructive conflict styles as the

Table 5

Positive Illusions and Changes in Satisfaction: Standardized Path Coefficients

\begin{tabular}{|c|c|c|c|}
\hline Path & Time 1 to Time 2 & Time 2 to Time 3 & Time 1 to Time 3 \\
\hline \multicolumn{4}{|c|}{ Initial reality paths } \\
\hline $\begin{array}{l}\text { e: Male partner's self-image } \\
\text { e': Female partner's self-image } \\
\text { a: Female actor's self-image } \\
\text { a': Male actor's self-image }\end{array}$ & $\begin{array}{l}.157^{*} \\
.157^{*} \\
.058 \\
.058 \\
\end{array}$ & $\begin{array}{l}-.122 \\
.293^{*} \\
.011 \\
.011 \\
\end{array}$ & $\begin{array}{l}.043 \\
.390^{* * *} \\
-.104 \\
.234^{*} \\
\end{array}$ \\
\hline \multicolumn{4}{|c|}{ Initial projection paths } \\
\hline $\begin{array}{l}\text { b: Female actor's ideals } \\
\text { b': Male actor's ideals } \\
\text { c: Female's projected illusions } \\
\text { c: Male's projected illusions } \\
\text { f and f': Reflected illusions }\end{array}$ & $\begin{array}{l}-.170 \\
.237^{* *} \\
.106 \\
.106 \\
-.039 \\
\end{array}$ & $\begin{array}{r}-.057 \\
-.057 \\
.114 \\
.114 \\
.080 \\
\end{array}$ & $\begin{array}{l}-.023 \\
-.026 \\
.334^{* *} \\
.090 \\
.077 \\
\end{array}$ \\
\hline \multicolumn{4}{|c|}{ Stability paths $\mathbf{s}^{\mathbf{a}}$} \\
\hline $\begin{array}{l}\text { d: Female's initial reports of satisfaction } \\
\text { d': Male's initial reports of satisfaction }\end{array}$ & $\begin{array}{l}.217^{* *} \\
.217^{* *}\end{array}$ & $\begin{array}{l}.640^{* * *} \\
.345^{* * * *}\end{array}$ & $\begin{array}{l}.021 \\
.021\end{array}$ \\
\hline
\end{tabular}

Note. See Figure 4 for paths. Time 1 to Time 2: goodness-of-fit index $(\mathrm{GFI})=.94$, comparative fit index $(\mathrm{CFI})=1.0, \chi^{2}(23, N=73)=23.11, n s$. Time 2 to Time $3: \mathrm{GFI}=.92, \mathrm{CFI}=.99, \chi^{2}(22, N=53)=25.49$, $n s$. Time 1 to Time 3: $\mathrm{GFI}=.96, \mathrm{CFI}=1.0, \chi^{2}(21, N=58)=13.63, n s$.

At Time 2 to Time 3 , the stability paths $d$ and d' are significantly different, $\chi^{2}(1, N=53)=10.22, p<.05$.

$* p<.10 . * * p<.05$. ${ }^{* * *} p<.01$. 
Table 6

Positive Illusions and Changes in Conflict: Standardized Path Coefficients

\begin{tabular}{|c|c|c|c|}
\hline Path & Time 1 to Time 2 & Time 2 to Time 3 & Time 1 to Time 3 \\
\hline \multicolumn{4}{|c|}{ Initial reality paths } \\
\hline $\begin{array}{l}\text { e and } \mathrm{e}^{\prime}: \text { Partner's self-image } \\
\text { a and } \mathbf{a}^{\prime}: \text { Actor's self-image }\end{array}$ & $\begin{array}{l}-.054 \\
-.059\end{array}$ & $\begin{array}{r}.018 \\
-.071\end{array}$ & $\begin{array}{l}-.088 \\
-.085\end{array}$ \\
\hline \multicolumn{4}{|c|}{ Initial projection paths } \\
\hline $\begin{array}{l}\text { b: Female actor's ideals } \\
b^{\prime}: \text { Male actor's ideals } \\
\text { c and } c^{\prime}: \text { Projected illusions } \\
\text { f and } \mathbf{f}^{\prime}: \text { Reflected illusions }\end{array}$ & $\begin{array}{l}.103 \\
-.224^{* *} \\
.021 \\
.020\end{array}$ & $\begin{array}{l}-.025 \\
-.025 \\
.021 \\
-.238^{* * *}\end{array}$ & $\begin{array}{l}-.131 \\
-.131 \\
-.024 \\
-.185^{* *}\end{array}$ \\
\hline \multicolumn{4}{|c|}{ Stability paths } \\
\hline d and d': Initial reports of conflict & $.530^{* * *}$ & $.560^{* * *}$ & $.289^{* * *}$ \\
\hline
\end{tabular}

Note. See Figure 4 for paths. Time 1 to Time 2: goodness-of-fit index $(G F I)=.93$, comparative fit index $(\mathrm{CFI})=.97, \chi^{2}(23, N=73)=30.86, n s$. Time 2 to Time $3: \mathrm{GFI}=.91, \mathrm{CFI}=.99, \chi^{2}(24, N=53)=27.07$, $n s$. Time 1 to Time 3: GFI $=.93, \mathrm{CFI}=1.0, \chi^{2}(24, N=58)=21.85$, ns.

** $p<.05$. *** $p<.01$.

year progressed. Individuals reported relatively less frequent conflicts at Time 3 when their partners idealized them at Time 1 , as shown by the significant pooled reflected illusion paths ( $f$ and $\mathbf{f}^{\prime}$ ). Identical effects of being idealized emerged from Time 2 to Time 3 . Conflicts actually declined when intimates idealized one another the most and increased when they idealized one another the least. Furthermore, individuals reported relatively less destructive conflict styles at Time 3 when they idealized their partners and their partners idealized them at Time 1. The projected illusion paths ( $c$ and $c^{\prime}$ ) were significant and the reflected illusion paths ( $f$ and $f^{\prime}$ ) were marginal. Identical (and even stronger) effects of idealizing and being idealized on reports of destructive conflicts emerged over the 8 months from Time 2 to Time 3.
Most critical, this evidence for the role of idealization in minimizing conflicts was not simply a result of being in a satisfying relationship. Both projected and reflected illusions continued to predict significant changes in the frequency and destructiveness of conflicts even when we controlled for both the actor's and the partner's satisfaction. Indeed, neither actors' nor partners' initial feelings of satisfaction predicted changes in their experience of conflict. These findings suggest that idealizing a partner and being idealized exert unique effects in developing romances, a protective influence that is not extended by more diffuse feelings of satisfaction.

Just as with the results for satisfaction, certain reality effects also emerged over time. Intimates' real attributes predicted changes in destructive conflicts. As the significant partner real-

Table 7

Positive Illusions and Changes in Destructiveness: Standardized Path Coefficients

\begin{tabular}{|c|c|c|c|}
\hline Path & Time 1 to Time 2 & Time 2 to Time 3 & Time 1 to Time 3 \\
\hline \multicolumn{4}{|c|}{ Initial reality paths $s^{\mathrm{a}}$} \\
\hline $\begin{array}{l}\text { e: Male partner's self-image } \\
\text { e': Female partner's self-image } \\
\text { a and a': Actor's self-image }\end{array}$ & $\begin{array}{l}-.168^{* *} \\
-.168^{* *} \\
-.220^{* * *}\end{array}$ & $\begin{array}{r}.153 \\
-.117 \\
.083\end{array}$ & $\begin{array}{l}-.127 \\
-.127 \\
-.190^{* *}\end{array}$ \\
\hline \multicolumn{4}{|c|}{ Initial projection paths } \\
\hline $\begin{array}{l}\text { b: Female actor's ideals } \\
b^{\prime} \text { : Male actor's ideals } \\
\text { c and c': Projected illusions } \\
\text { f and f': Reflected illusions }\end{array}$ & $\begin{array}{l}.115^{*} \\
.115^{*} \\
.055 \\
.006\end{array}$ & $\begin{array}{l}-.002 \\
-.002 \\
-.266^{* *} \\
-.172^{* *}\end{array}$ & $\begin{array}{l}.297^{* * * *} \\
-.035 \\
-.181^{* * *} \\
-.125^{*}\end{array}$ \\
\hline \multicolumn{4}{|c|}{ Stability paths } \\
\hline d and d': Initial reports of destructiveness & $.548^{* * *}$ & $.520^{* * *}$ & $.395^{* * *}$ \\
\hline
\end{tabular}

Note. See Figure 4 for paths. Time 1 to Time 2 : goodness-of-fit index $(\mathrm{GFI})=.90$, comparative fit index $(\mathrm{CFI})=.94, \chi^{2}(24, N=73)=44.77, p<.05$. Time 2 to Time $3: \mathrm{GFI}=.90, \mathrm{CFI}=.98, \chi^{2}(23, N=53)=$ $30.67, n s$. Time 1 to Time 3: GFI $=.94, \mathrm{CFI}=1.0, \chi^{2}(23, N=58)=20.38, n s$.

at Time 2 to Time 3 , the partner reality paths $e$ and $e^{\prime}$ are significantly different, $\chi^{2}(1, N=53)=5.49$, $p<.05$.

$* p<.10 . \quad * * p<.05 . \quad * * * p<.01$. 
ity paths ( $e$ and $e^{\prime}$ ) illustrate, individuals reported relatively less destructive conflicts at Time 2 the more positive their partners' self-images were at Time 1. Individuals' own self-images also forecast changes in conflict. The more positive actors' self-images were at Time 1 , the relatively less destructive conflicts they reported at Time 3, as the significant paths for actors' attributes (a and $\mathbf{a}^{\prime}$ ) illustrate. Conversely, the less positive actors' selfimages were at Time 1 , the more destructive conflicts they reported at Time 3. An identical effect emerged from Time 1 to Time 2.

Unfulfilled ideals-a partner's failing to live up to one's hopes-again affected men's and women's reports of conflict differently. Paralleling the results for satisfaction, unfulfilled ideals at Time 1 predicted relatively more destructive conflicts at Time 3 for women (path $\mathbf{b}$ ), but not for men (path $\mathbf{b}^{\prime}$ ), $\chi^{2}$ ( 1 , $N=58)=7.15, p<.05$. Women's reports of destructive conflicts increased relatively more the higher their ideals, and decreased the less exacting their ideals. A similar pattern was evident for conflict frequency for women. But for men, high (and unmet) ideals at Time 1 predicted relatively less frequent conflicts at Time 2 (path b'), $\chi^{2}(1, N=73)=7.47, p<.05$.

Warding off doubts? Apart from warding off conflicts, seeing a partner in the most tolerant or generous light possible might even protect intimates from experiencing renewed qualms or doubts about a partner's imperfections. The trait ambivalence measure obtained at Time 3 indexed such conflicted feelings about a partner's qualities (e.g., believing that the same attributes were both good and bad). Figure 1 presents the template for the model we used to link initial positive illusions to later ambivalence. Simply imagine that the criterion (in the final box) is later ambivalence instead of concurrent well-being. Table 8 presents the pooled path coefficients linking idealization at Times 1 and 2 to ambivalence or doubt at Time 3 .

As we hypothesized, idealizing a partner and being idealized initially predicted relatively less ambivalence or fewer doubts at year's end. Both the pooled projected ( $h$ and $h^{\prime}$ ) and reflected ( $j$ and $\mathbf{j}^{\prime}$ ) illusions paths were significant. Identical effects emerged from Time 2 to Time 3. In fact, early idealization predicted fewer doubts at Time 3 even when we controlled for the actor's and the partner's Time 1 satisfaction. In contrast, social realities

Table 8

Initial Illusions and Later Trait Ambivalence: Standardized Path Coefficients

\begin{tabular}{lcc}
\hline \multicolumn{1}{c}{ Path } & Time 2 to Time 3 & Time 1 to Time 3 \\
\hline \multicolumn{3}{c}{ Initial reality paths } \\
i and i': Partner's self-image & .134 & -.038 \\
f and f': Actor's self-image & .067 & -.089 \\
\hline \multicolumn{3}{c}{ Initial projection paths } \\
g and g:: Actor's ideals & .011 & -.007 \\
h and h': Projected illusions & $-.383^{* * *}$ & $-.263^{* * *}$ \\
j and $\mathbf{j}^{\prime}:$ Reflected illusions & $-.488^{* * *}$ & $-.321^{* * *}$ \\
\hline
\end{tabular}

Note. See Figure 1 for paths. Time 2 to Time 3: goodness-of-fit in$\operatorname{dex}(\mathrm{GFI})=.95$, comparative fit index $(\mathrm{CFI})=1.0, \chi^{2}(14, N=53)=$ $13.02, n s$. Time 1 to Time 3: $\mathrm{GFI}=.95, \mathrm{CFI}=1.0, \chi^{2}(14, N=58)$ $=11.00, n s$.

$* * * p<.01$. at Times 1 and 2 , including the actor's attributes (paths $f$ and $\left.f^{\prime}\right)$, the partner's real qualities ( $i$ and $i^{\prime}$ ), and unfulfilled ideals ( $g$ and $\mathbf{g}^{\prime}$ ) did not predict later ambivalence. As these results illustrate, idealizing a partner appeared to provide a built in "Yes, but . . ." that protected individuals from entertaining serious doubts about their partners' apparent virtues and frailties. And again, the protective influence of idealization was not shared by simple reports of happiness.

Mutual understanding and changes in well-being. The results of the path models suggest that directional misunderstandings (or positive illusions) have a number of self-fulfilling effects. Relationships generally became more satisfying and less distressing when individuals idealized their partners and their partners idealized them. To see if accurately understanding a partner's global self-regard had any effects on later adjustment, we obtained estimates for a series of models that predicted changes in well-being (e.g., satisfaction, conflict, or doubt) from the actor's perception of the partner, the partner's self-image, and the understanding interaction terms. Again, no consistent, significant effects of understanding emerged. Instead, mirroring the results of the path models, individuals generally became happier (or less distressed) the more positive their impressions of one another, holding the reality of one another's attributes constant.

Fulfilling hopes: A summary. Idealizing a partner appeared to create the realities intimates desired as these romances developed by insulating them from the increasing conflicts and waning satisfaction apparent in the general sample. For women, idealizing a partner resulted in their feeling relatively happier at year's end. And for both women and men, idealizing a partner and being idealized resulted in intimates experiencing relatively less conflict and less ambivalence (in comparison with less idealistic intimates) as these romances developed. These effects were even strong enough to work against any countervailing tendencies toward regression to the mean. For instance, a regression account would predict that women who idealized their partners the most would be most likely to suffer declines in satisfaction given some error in measurement. Instead, in this (and all other cases), the "rich continued to get richer and the poor, poorer."11

The findings thus far suggest that idealization forecasts later well-being, as we proposed in our original model. We also examined a series of models testing the reverse causal link-those between initial well-being (e.g., satisfaction, ambivalence, or conflict) and later idealization. Only two effects emerged. Greater satisfaction at Time 2 predicted relatively more idealized impressions of one's partner by Time 3. Also, experiencing destructive conflicts at Time 1 resulted in relatively less idealized images of one's partner by Time 2 . Such results suggest that unhappy realities may tax intimates' ability to idealize one another. But overall, the results support the idea that illusions play a greater role in structuring later experiences than vice versa.

\footnotetext{
"This is not to deny that attention to measurement issues is terribly important in this field and that a multiple indicator approach permitting the estimation of latent variables and adjusting for attenuation would be valuable.
} 


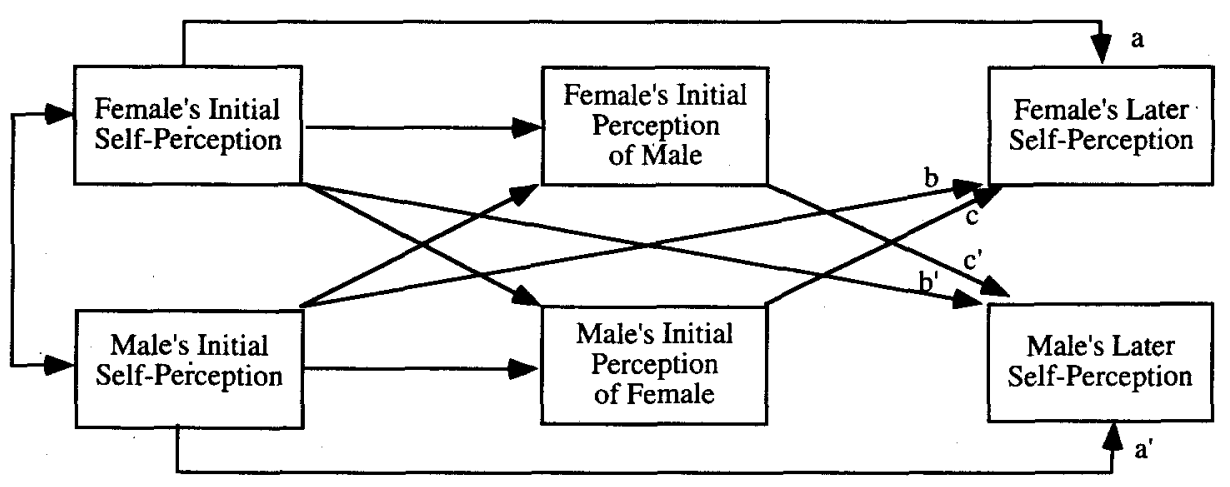

Figure 5. Being idealized and changes in models of self.

\section{Basking in Reflected Glory: Changing Models of Self}

Can intimates actually turn self-perceived frogs into princes or princesses, as we hypothesized? Swann et al. (1994) believe that intimates resist unfounded flattery and cling to their own self-images. However, if self-knowledge is susceptible to reflected appraisal, individuals might actually create the partners they desire by idealizing them (i.e., the reflected appraisal hypothesis). If idealization has such self-fulfilling effects, individuals should come to share their partners' rosy views of them as romances develop. Such transformations of self might surface on both the Interpersonal Qualities Scale and the measure of attachment style.

Figure 5 presents the model linking reflected appraisals to changing models of self, as tapped by the Interpersonal Qualities Scale. In this model, changes in self-concept are residualized effects (e.g., variance in Time 2 self-ratings that is not due to Time 1 self-ratings). Paths $\mathbf{a}$ and $\mathbf{a}^{\prime}$ index the degree of stability in self-perceptions. The self-projection paths $\mathbf{b}$ and $\mathbf{b}^{\prime}$ index whether the actor's attributes predict changes in the partner's self-image (i.e., whether intimates become more similar). The reflected illusion paths $c$ and $c^{\prime}$ index the link between the actor's initial illusions and changes in the partner's self-perceptions. More simply, these paths tap whether being idealized changes individuals' self-views.

Table 9 presents the pooled, standardized path coefficients for this model for each time interval. The self-projection paths b and b' were not significant, suggesting that individuals did not come to see themselves as more like their partners as time passed. Instead, intimates appeared to bask in their partners' reflected appraisals. Being idealized at Time 1 predicted relatively more positive self-perceptions at Times 2 and 3 , as the reflected illusion paths $\mathbf{c}$ and $\mathbf{c}^{\prime}$ were both significant. When their partners idealized them most at Time 1 , individuals' selfperceptions grew more positive by Time 3 . Conversely, when their partners idealized them least, individuals' self-perceptions grew less positive at Time 3. These effects of reflected illusions also surfaced from Time 2 to Time 3. Most critically, this evidence for the transmission of illusions was not simply a result of individuals being involved in a satisfying relationship. Being idealized continued to predict significant changes in individuals' self-perceptions whether we controlled for the actor's (i.e., perceiver's) or the partner's (i.e., target's) satisfaction.

Did basking in the glow of a partner's rosy regard also chal- lenge (or change) intimates' models of self on the attachment dimensions? Figure 6 presents the model we used to explore this question. Griffin and Bartholomew's (1994) formula for computing the positivity of attachment models of self (and other) is described in the Method section. New to this model, paths $b$ and $\mathbf{b}^{\prime}$ represent social reality effects, tapping the link between perceptions of a partner and the partner's self-models. Paths $\mathbf{a}$ and $\mathbf{a}^{\prime}$ index projection, assessing whether individuals project their own securities (or insecurities) onto their partners. Paths $\mathbf{e}$ and $\mathbf{e}^{\prime}$ index the stability of attachment models of self. Paths $i$ and $i$ ' index whether partners' self-models become more similar over time. The reflected appraisal paths $\mathbf{h}$ and $\mathbf{h}^{\prime}$ link being idealized to changes in working models of the self on the attachment dimensions.

Figure 6 also contains the pooled path coefficients for this model. The projection of intimates' general securities (or insecurities) shaped their impressions of their partners, as the significant self-projection paths $\mathbf{a}$ and $\mathbf{a}^{\prime}$ illustrate. The more secure intimates' models of self, the rosier their illusions about their partners. Conversely, the less secure their self-models, the less idealized their impressions of their partners. Turning to the longitudinal effects, women's models of self on the attachment measure (path e) were more stable over the year than were men's models of self ( path $\mathrm{e}^{\prime}$ ), $\chi^{2}(1, N=58)=9.30, p<.05$. Most critical, being idealized predicted changes in women's, but not men's, models of self, as the significant reflected illusion path $\mathbf{h}$ illustrates. Women became relatively more secure in their attachment styles by year's end the more their partners idealized them at Time 1. As time passed, intimates appeared to create the partners they desired by idealizing them, turning self-perceived frogs into the princes or princesses they perceived. (No consistent effects emerged predicting changes in men's or women's general models of others).

\section{Self-Corrective Mechanisms? Keeping Idealization Within Reasonable Bounds}

Rather than leaving individuals vulnerable to disappointment, seeing a partner who mirrors their hopes and ideals seems to protect and even strengthen developing romances. Some degree of (apparent) ignorance, then, appears to breed romantic bliss. But some readers might be wondering how to reconcile these findings with decades of wisdom indicating that 
Table 9

Reflected Illusions and Changes in Models of Self: Standardized Path Coefficients

\begin{tabular}{|c|c|c|c|}
\hline Path & Time 1 to Time 2 & Time 2 to Time 3 & Time 1 to Time 3 \\
\hline \multicolumn{4}{|c|}{ Initial projection paths } \\
\hline $\begin{array}{l}\text { b and } b^{\prime}: \text { Partner's self-perceptions } \\
c \text { and } c^{\prime}: \text { Reflected illusions }\end{array}$ & $\begin{array}{l}.086 \\
.143^{* *}\end{array}$ & $\begin{array}{l}.002 \\
.152^{*}\end{array}$ & $\begin{array}{l}-.014 \\
.291^{* * *}\end{array}$ \\
\hline \multicolumn{4}{|c|}{ Stability paths } \\
\hline $\mathbf{a}$ and $\mathbf{a}$ : Original self-perceptions & $.640^{* * *}$ & $.625^{* * *}$ & $.529 * * *$ \\
\hline
\end{tabular}

reality monitoring is critical for well-functioning relationships (whereas others might be wondering how they might encourage a little more myopia on their partners' part!).

The fact that basking in the warm glow of a partner's idealized regard actually changes intimates' self-esteem might be one mechanism that keeps the idealization process within bounds (i.e., in touch with [an altered] reality). Moreover, we suspect that idealization retains its benefits partly because intimates actually accommodate their desires and perceptions to reality. For instance, individuals might come to better understand their partners' actual qualities as time passes. But even accommodating perceptions to a partner's "real" qualities need not unduly tarnish perceptions if individuals restructure their ideals in their partners' image. Continuing to project one's own rosy self-image on a partner may similarly sustain idealization as time passes.

Accommodating perceptions to reality? Figure 7 presents the model we used to explore changes in individuals' impressions of their partners. In this model, changes in impressions are residualized effects (e.g., variance in Time 2 impressions

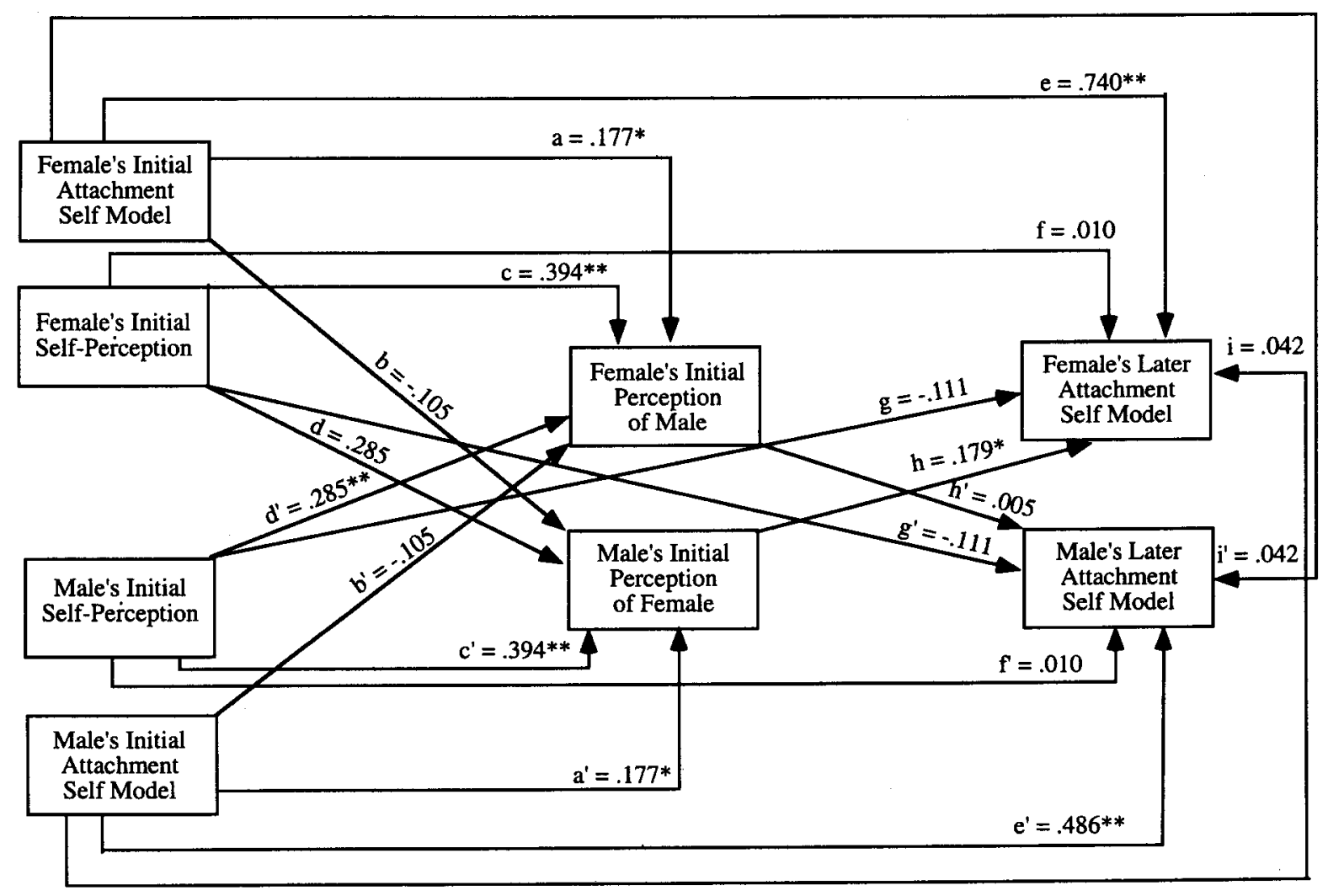

Figure 6. Being idealized and changes in attachment orientations. Goodness-of-fit-index $=.96$, comparative fit index $=.98, \chi^{2}(9, N=58)=11.18, n s .{ }^{*} p<.05 . * * p<.01$. 


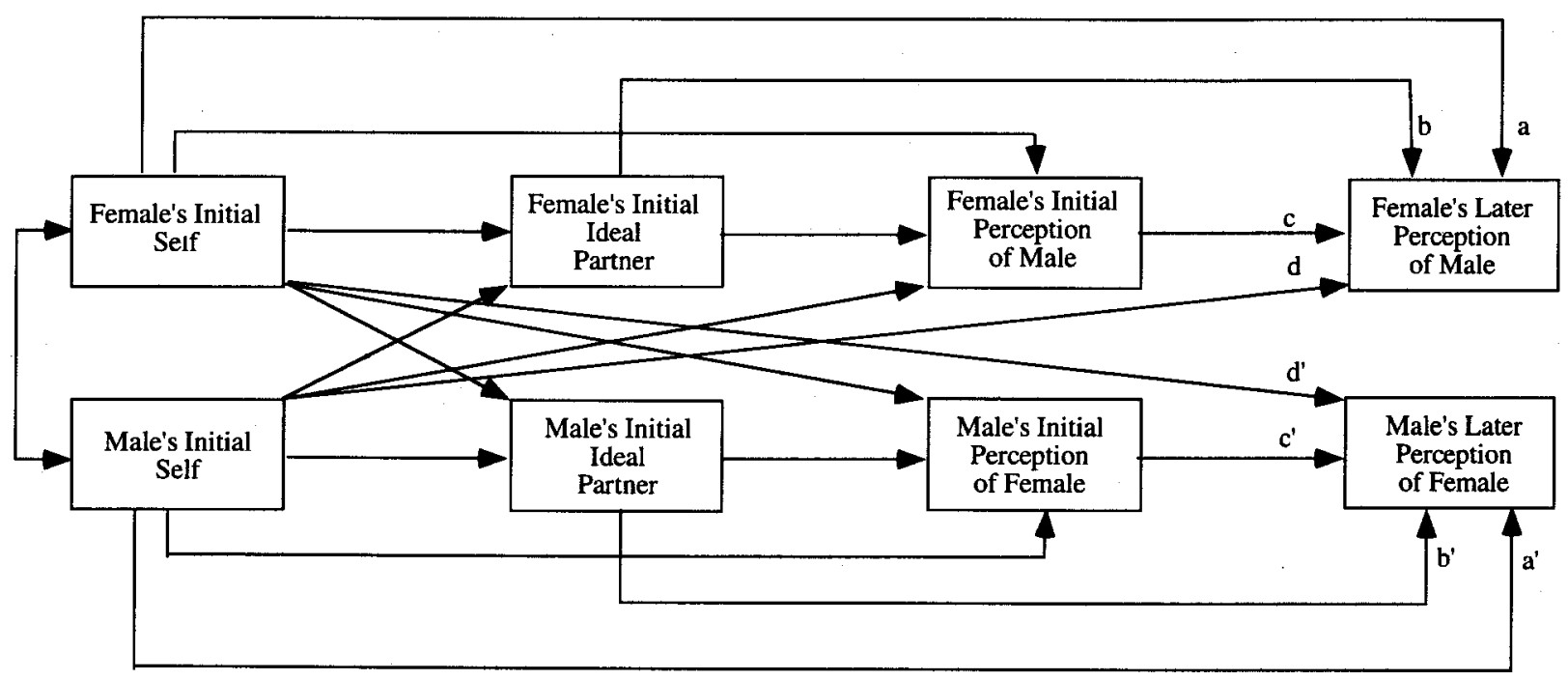

Figure 7. Models of self and ideals and changes in impressions of partners.

that is not due to Time 1 impressions). Paths $\mathbf{c}$ and $\mathbf{c}^{\prime}$ index stability or continuity in perceptions of one's partner. Paths d and $\mathbf{d}^{\prime}$ represent social reality effects, tapping whether impressions accommodate to the partner's real qualities. In contrast, paths a and $\mathbf{a}^{\prime}$ represent self-projection paths, which tap whether actors' self-images predict changes in their illusions. And finally, the ideal-projection paths $b$ and $b^{\prime}$ link unfulfilled ideals to changes in perceptions. Again, each path represents a partial or unique effect.

Table 10 presents the pooled, standardized path coefficients tracing changes in actors' impressions of their partners at each time interval. As we suspected, intimates' perceptions of their partners accommodated somewhat to the constraints imposed by their partners' actual qualities. Time 2 reality paths ( $d$ and $d^{\prime}$ ) predicted changes in intimates' perceptions of their partners at Time 3. When intimates' self-images were relatively poor at Time 2, their partners came to see them in a less idealized light at Time 3. Conversely, when individuals' self-images were rosier at Time 2, their partners' impressions of them grew relatively more positive by Time 3 . Parallel reality effects emerged predicting changes in men's impressions from Time 1 to Time 2 and from Time 1 to Time 3. Men's impressions of women accommodated somewhat to women's reality, but women's perceptions of men did not: $\chi^{2}(1, N=73)=3.34, p<.10$, and $\chi^{2}(1, N=57)=5.32, p<.05$, respectively.

Projection also continued to shape men's impressions of women. Men's projection of their own self-images onto their partners shaped changes in their Time 3 impressions, as the significant self-projection path a' illustrates. When men thought less of themselves at Time 1 , they had greater difficulty holding

Table 10

Predicting Changes in Individuals' Impressions of Their Partners: Standardized Path Coefficients

\begin{tabular}{|c|c|c|c|}
\hline Path & Time 1 to Time 2 & Time 2 to Time 3 & Time 1 to Time 3 \\
\hline \multicolumn{4}{|c|}{ Initial reality paths } \\
\hline $\begin{array}{l}\text { d: Reflection of male partner's self-image } \\
\text { d: Reflection of female partner's self-image }\end{array}$ & .017 & $\begin{array}{l}.197^{* * * *} \\
.197^{* * * *} \\
\end{array}$ & $\begin{array}{l}.104 \\
.296^{* * *} \\
\end{array}$ \\
\hline \multicolumn{4}{|c|}{ Initial projection paths } \\
\hline $\begin{array}{l}\text { a: Projection of female actor's self-image } \\
\text { a': Projection of male actor's self-image } \\
\text { b and b': Projection of actor's ideals }\end{array}$ & $\begin{array}{l}.087 \\
.215^{* *} \\
.012 \\
\end{array}$ & $\begin{array}{l}-.016 \\
-.016 \\
-.002\end{array}$ & $\begin{array}{l}.058 \\
.230^{* *} \\
-.035\end{array}$ \\
\hline \multicolumn{4}{|c|}{ Stability paths } \\
\hline$c$ and $c^{\prime}$ : Original perceptions of partner & $.554^{* * *}$ & $.696^{* * *}$ & $.549^{* * * *}$ \\
\hline
\end{tabular}

Note. See Figure 7 for paths. Time 1 to Time 2: goodness-of-fit index $(\mathrm{GFI})=.95$, comparative fit index $(\mathrm{CFI})=.98, \chi^{2}(13, N=73)=17.64, n s$. Time 2 to Time $3: \mathrm{GFI}=.93, \mathrm{CFI}=.99, \chi^{2}(15, N=52)=17.09$, ns. Time 1 to Time 3: $\mathrm{GFI}=.93, \mathrm{CFI}=.97, \chi^{2}(13, N=57)=17.67$, ns.

${ }^{* *} p<.05$. ${ }^{* * *} p<.01$. 
Table 11

Accommodating Images of the Ideal Partner to Perceived Partners: Standardized Path Coefficients

\begin{tabular}{|c|c|c|c|}
\hline Path & Time 1 to Time 2 & Time 2 to Time 3 & Time 1 to Time 3 \\
\hline \multicolumn{4}{|c|}{ Initial reality paths } \\
\hline d and d': Reflection of partner's self-image & .080 & .046 & .073 \\
\hline \multicolumn{4}{|c|}{ Initial projection paths } \\
\hline $\begin{array}{l}\mathbf{a} \text { and } \mathbf{a}^{\prime}: \text { Projection of actor's self-image } \\
\mathbf{b} \text { and } \mathbf{b}^{\prime} \text { : Actor's initial image of partner }\end{array}$ & $\begin{array}{l}.259^{* * *} \\
.135^{*} \\
\end{array}$ & $\begin{array}{l}.145^{*} \\
.159^{*} \\
\end{array}$ & $\begin{array}{l}.264^{* * *} \\
.227^{* * *} \\
\end{array}$ \\
\hline \multicolumn{4}{|c|}{ Stability paths } \\
\hline c and $c:$ Original images of the ideal partner & $.342^{* * *}$ & $.521^{* * *}$ & $.318^{* * *}$ \\
\hline
\end{tabular}

onto their illusions about their partners by Time 3 . But when men's self-perceptions were rosier, their impressions of their partners grew relatively more idealized. In contrast, women's initial self-perceptions did not predict changes in their impressions of their partners at Time $3, \chi^{2}(1, N=57)=4.00, p<$ .05. [An identical self-projection effect for men, but not women, also emerged from Time 1 to Time $2, \chi^{2}(1, N=73)=3.34, p$ $<$.10.] However, parallel self-projection effects emerged (from Time 1 to Time 2 and from Time 1 to Time 3 ) for both women and men when we used Rosenberg's (1965) Self-Esteem Scale as the index of self-models. Intimates with higher self-esteem projected such positive regard onto their partners, coming to see them all the more positively as these romances progressed. The ideal-projection paths ( $b$ and $\mathbf{b}^{\prime}$ ) did not predict changes in intimates' perceptions of their partners across any of the time periods. $^{12}$

Accommodating desires to perceptions? Instead, ideals consistently accommodated to the attributes individuals perceived in their partners (but not to the attributes that actually existed). This effect emerged when we examined revised models in which initial impressions of one's partner (a criterion in Figure 7) predicted changes in one's ideals ( the predictor in Figure 7). Table 11 contains the pooled path coefficients for this revised model. Seeing greater virtue in a partner initially resulted in intimates maintaining relatively high ideals, as the significant accommodation paths ( $b$ and $\mathbf{b}^{\prime}$ ) illustrate. Conversely, intimates who perceived fewer virtues in their partners early on revised their ideals downward as time passed. Such results suggest that individuals maintain positive illusions (in part) by constructing self-serving models of the ideal partner-a backward type of logic that leads intimates to define the attributes they perceive in their partners as ideal (e.g., Kunda, 1987; Murray \& Holmes, 1993, 1994). As we suspected, certain self-corrective mechanisms seem to keep idealization within reasonable, beneficial bounds.

\section{Discussion}

Despite occasional intrusions of reality, the lovers in this study who subscribed to William Blake's vision of love did not end up disappointed and disillusioned. Instead, relationships persisted and became more satisfying and less distressing when intimates idealized one another the most, not when they more accurately understood one another's frailties. In fact, we argue that lovers who subscribed to William Blake's vision of love are not so much blind and prone to disappointment as prescient, actually creating hoped-for realities as time passes. ${ }^{13}$

\footnotetext{
${ }^{12}$ When the self-projection paths were omitted from the models, men's ideals did predict changes in their impressions of their partners over the year. The higher their initial ideals, the more idealized their later perceptions of their partners.

${ }^{13}$ We also found strong evidence of the self-fulfilling effects of idealization when we examined simplified models using ordinary least squares regression. For illustrative purposes, we present only selected results concerning changes in men's feelings and perceptions. In these simplified models, idealizing a partner refers to the effects of men's perceptions of women, controlling for women's self-perceptions, whereas being idealized refers to the effects of women's perceptions of men, controlling for men's self-perceptions. Turning first to the buffering hypothesis, idealizing a partner buffered or protected men from the disruptive effects of negativity, $\beta_{\text {interaction }}=.208, p<.05$. Turning to the transformation hypothesis, being idealized by a partner initially resulted in men reporting fewer conflicts at year's end, $\beta_{\text {Time } 1-\text { Time } 3}=-.294, p<.05$ and $\beta_{\text {Time 2-Time } 3}=-.284, p<.01$, and idealizing a partner early on predicted less destructive conflicts at Time $3, \beta=-.324, p<.05$. Similarly, idealizing and being idealized by a partner at Times 1 and 2 resulted in men feeling less conflicted or uncertain about their partners by year's end: $\beta \mathrm{T} 1-\mathrm{T} 3_{\text {projected }}=-.242, p<.07, \beta \mathrm{T} 1-\mathrm{T} 3_{\text {reflected }}=-.492, p<.01$; $\beta \mathrm{T} 2-\mathrm{T} 3_{\text {projected }}=-.389, p<.01, \beta \mathrm{T} 2-\mathrm{T} 3_{\text {reflected }}=-.557, p<.01$. With regard to the reflected appraisal hypothesis, being idealized by their partners at Time 1 resulted in men feeling even better about themselves by Times 2 and 3: $\beta_{\mathrm{T} 1-\mathrm{T} 2}=.205, p<.05$ and $\beta_{\mathrm{T} 1-\mathrm{T} 3}=.224, p<.05$. Similar evidence of the transforming effects of idealization were found when we used OLS regression to examine changes in women's perceptions. OLS regression also yielded social reality effects mirroring those already reported. For instance, men grew happier and more content in their relationships by year's end the rosier their partners' initial selfregard, $\beta_{\mathrm{T} 1-\mathrm{T} 3}=.432, p<.01$. And, in terms of self-corrective effects, men accommodated their perceptions to better reflect women's actual attributes as time went on, $\beta_{\mathrm{T} 1-\mathrm{T} 3}=.413, p<.01$.
} 


\section{Idealization or Understanding? Constructing a Lasting Sense of Security}

Love is a gross exaggeration of the difference between one person and everybody else.-George Bernard Shaw

Mirroring Shaw's musings, impressions of a romantic partner at each time period appeared to reflect a mixture of the real partner's attributes and the actor's wishes or hopes. These illusions-or motivated misunderstandings-reflected actors' tendency to project their own self-images and hopes for the ideal partner onto their actual partners. The more positive their selfimages and ideals, the more idealized their impressions of their partners. Positive illusions, then, appear to stem in part from individuals' own level of self-regard. Rosier self-regard predicted more positive images of an ideal partner and more idealized perceptions of one's own partner.

As these romances progressed, models of self predicted further revisions in models of intimate others. When men thought relatively less of themselves at Time 1 , they had greater difficulty holding onto their illusions about their partners. When their self-images were rosier, however, men's impressions of their partners grew relatively more idealized. Parallel self-projection effects emerged for both women and men when we used global self-esteem (i.e., the Rosenberg scale) to index models of the self. Women and men with higher self-esteem projected such positive regard onto their partners, coming to see their partners as more a mirror of their own self-images as time passed. Such results suggest that individuals form models of romantic others that mirror their own personal strengths or weaknesses (e.g., Baldwin, 1992; Griffin \& Bartholomew, 1994).

Further, the idealized images intimates constructed were intricately tied to well-being in these developing romances, as the concurrent projected and reflected illusions effects illustrate. Individuals were happier in their relationships when they idealized their partners, seeing virtues in them that their partners did not see in themselves. Intimates who idealized their partners more also reported less frequent and less destructive conflicts. And being the target of such idealized constructions also appeared to benefit well-being. Intimates were happier and reported less frequent, less destructive conflicts when their partners looked beyond the reality of their frailties and saw the best in them. Trait-specific illusions had similar, beneficial effects on well-being.

More accurately understanding a partner's self-image rarely predicted concurrent satisfaction. When it did (at Time 3), women who came to better understand their partners' self-perceived imperfections were actually least happy. In contrast to this effect, one might have expected actual understanding to benefit well-being precisely because intimates would know and understand one another's actual virtues and faults and still accept and love one another (Swann et al., 1994). After all, it might be quite disconcerting for individuals to believe that their partners are only in love with an illusion. The present results suggest that this intuitively compelling proposition may fall short because truly understanding a partner's faults more often diminishes positive regard than instills unconditional acceptance. But understanding a partner's self-schema may not have such costs. The indices of trait-specific understanding yielded some support for this hypothesis. Women and men were happier the better women understood men's self-schemas at Times 2 and 3. Overall though, the findings for current well-being suggest that happiness and security necessitate a certain degree of illusion or motivated inaccuracy.

Despite the rigors of time and the increased potential for disappointment, idealizing a partner predicted greater well-being and stability as these romances progressed. Intimates who idealized one another the most--whose perceptions departed most from reality-were involved in the most stable relationships. Romances were more likely to persist the more intimates idealized (or misunderstood) one another at both global and traitspecific levels. In fact, consistent with our buffering hypothesis, idealizing a partner actually insulated individuals from the deleterious effects of conflicts and doubts, apparently acting as a compensatory force (e.g., Gottman, 1994; Huston \& Chorost, 1994). When men idealized women the most, early conflicts and doubts did not trigger breakups; when men idealized women the least, relationships dissolved in response to early difficulties. Accurately understanding a partner's "real" qualities, however, had no relation to the relationship's stability.

As further evidence of idealization's self-fulfilling effects, positive illusions acted as a transformational force, warding off later disappointments and protecting intimates from the waning satisfaction and increasing conflicts apparent in the general sample. For women, idealizing a partner predicted relatively greater feelings of satisfaction at year's end. Even stronger idealization effects emerged in predicting later conflicts and doubts for both men and women-perhaps because of the often hypothesized role of positive illusions in warding off threats.

Idealizing a partner and being idealized (in particular) resulted in intimates reporting relatively less frequent and destructive conflicts despite the greater occasion to discover just how their needs did conflict. Such effects might emerge because intimates who idealize their partners expect their partners to treat them generously. This confidence in a partner's motives may foster the sense of trust and security intimates need in order to act selflessly in the face of conflicts, transforming them in ways that bridge apparently divergent interests and minimize overt conflicts (e.g., Kelley, 1979). Even when conflicts do occur, intimates who idealize one another may be more likely to find excuses for a partner's transgressions that minimize the significance of these misdeeds and prevent minor issues from escalating into serious conflicts (e.g., Bradbury \& Fincham, 1990).

Idealization also lessened the likelihood of individuals entertaining serious doubts or concerns as their romances progressed. Despite the increased opportunity for time to turn amusing foibles into intolerable faults, idealizing a partner and being idealized lessened the likelihood of intimates later doubting or questioning the actual merit of their partners' apparent virtues. Idealization may have this effect in suppressing ambivalence (and its renewal) because ideals provide a template for constructing a sense of conviction that resolves the tension between individuals' hopes and fears (e.g., Murray \& Holmes, 1993, 1994). From an attachment perspective, seeing a partner as (nearly) ideal may also foster a sense of internal peace or security that dampens concerns about the relationship's vulnerability to threats. In summary, positive illusions appeared to act as a transformational force in these developing relationships- 
bolstering later satisfaction, averting conflicts, and diminishing doubts. $^{14}$

\section{Basking in Reflected Glory: Constructing Actual Partners}

Despite Swann et al.'s (1994) claims that intimates resist unfounded flattery and cling to their self-images, individuals came to share their partners' rosy views of them as time passed. The more their partners idealized them initially, the more positive the changes in individuals' self-concepts. The opposite was true when their partners idealized them less. These rosy reflected appraisals even modified women's attachment styles-presumably chronic dispositions that originate in childhood and structure individuals' later romantic experiences (e.g., Bartholomew, 1990; Hazan \& Shaver, 1987). Women's self-models became relatively more secure the more their partners idealized them, suggesting that romantic experiences can influence attachment (as well as being influenced by it). As these romances progressed, individuals actually created the partners they perceived by idealizing them, transforming self-perceived frogs into the princes or princesses they desired. As far as we know, this is the first evidence relating changes in self-regard to qualities of relationships.

Such transformations of self illustrate how interactions with intimate others might shape and expand individuals' self-concepts, particularly in domains where self-knowledge is uncertain (cf. Aron et al., 1991, 1995; Baumeister \& Tice, 1986; M. R. Leary et al., 1995; McNulty \& Swann, 1994; Schlenker, 1986; Tice, 1992). A developing romance (especially if it is a first love) may play a large role in structuring individuals' models of themselves as romantic partners. Basking in the glow of a partner's rosy regard and acceptance may then shape and inform these developing self-concepts, as the present findings illustrate. Unconditional admiration may have these effects because individuals come to see their own qualities through their partners' more forgiving eyes. Also, individuals might directly contradict their partners' self-doubts or self-criticisms, thereby bolstering their partners' sense of self-worth. Individuals might even come to see themselves in a rosier light simply because their partners treat them as special, unique individuals and encourage more positive behavior on their part (e.g., Snyder et al., 1977).

In developing romances, self-concept change most likely occurs in domains where individuals aspire to certain "possible" selves but are unsure they have attained them. For instance, Hillary might readily accept Bill's appraisal of her empathy if she wants to see herself as a warm and caring partner, particularly if she fears she can be too impatient at times. Where selfknowledge is more certain, however, a partner's admiration may have less power to change individuals' self-concepts (e.g., Swann, 1987). Bill may have little success in convincing Hillary that she is athletically skilled if she is convinced of her clumsiness.

In summary, basking in the glow of a partner's rosy regard left individuals feeling even more secure in their own sense of self-worth as these romances developed. In turn, feeling more secure in their own sense of self might then have allowed individuals to see their partners in an even more positive or generous light (because of the role of positive self-regard in fostering illusions). This process of mutual affirmation and reaffirmation may be the keystone for lasting satisfaction and security in romantic relationships ( Reis \& Shaver, 1988).

\section{Self-Corrective Mechanisms? Keeping Idealization Within Reasonable Bounds}

The fact that basking in the warm glow of a partner's idealized regard actually changes intimates' self-esteem might be one mechanism that keeps the idealization process in touch with (an altered) reality. Idealization may also retain its benefits over time-instead of setting intimates up for disappointment-because intimates actually accommodate their desires and perceptions to reality.

That is, individuals adjusted their impressions of their romantic partners to the constraints imposed by the "real" partner's qualities as time passed, consistent with a basic premise of self-verification theory (e.g., McNulty \& Swann, 1994). "Actual" attributes that individuals once ignored (or failed to see) predicted changes in their perceptions. When partners' self-images were relatively poor at Time 2 , actors saw their partners in a relatively less idealized light by Time 3 . Conversely, when partners' self-images were rosier at Time 2, actors' impressions of their partners grew relatively more positive. Parallel effects of women's actual attributes on men's later perceptions also emerged from Time 1 to Time 2 and from Time 1 to Time 3 . The critical caveat with regard to the benefits of illusions, then, is that idealized images are most vulnerable when they are most out of touch with the partner's reality.

Ironically, even increased understanding need not unduly tarnish perceptions if intimates restructure their ideals in their partners' image. Intimates in stable relationships actually accommodated their ideals to incorporate the attributes they perceived in their partners (not the attributes that actually existed). Individuals who perceived relatively fewer virtues in their partners initially fashioned relatively lower ideals as time passed. Conversely, seeing greater virtue in a partner initially resulted in intimates setting even more hopeful ideals. Such results suggest that individuals maintain positive illusions in part by revising their ideal templates-a type of backwards or selfprotective logic that leads intimates to define the attributes they perceive in partners as ideal (e.g., Dunning \& McElwee, 1995; Dunning, Meyerowitz, \& Holzberg, 1989; Kunda, 1987; Murray \& Holmes, 1993, 1994). Through these three self-corrective, potentially interrelated mechanisms, idealization may be kept within reasonable, beneficial bounds.

\section{A Role for Reality: Working Models of Self}

Despite the self-fulfilling effects of idealization, certain realities did penetrate intimates' defenses as these romances developed. Attributes that individuals once ignored ( or failed to see)

\footnotetext{
${ }^{14}$ These various findings in support of the wish-fulfilling effects of idealization follow on the heels of a large literature arguing that optimism or idealism is critical for well-being (e.g., Greenwald, 1980; Janoff-Bulman, 1989; Scheier \& Carver, 1992; Taylor \& Brown, 1988; Taylor, Collins, Skokan, \& Aspinwall, 1989; Weinstein, 1980). From this perspective, happiness rests on people's ability to see a sometimes stern reality in the best possible light.
} 
in their partners predicted changes in reports of satisfaction, doubt, and conflict. In the first $\mathbf{4}$ months, intimates' satisfaction grew when their partners' self-images were relatively rosy and suffered more when their partners were more self-deprecating. Over the year, men grew relatively happier the rosier women's initial self-regard. Similar effects emerged for feelings of ambivalence, as indexed by the Braiker and Kelley (1979) scale. When their partners were more self-deprecating, intimates reported feeling relatively more doubt about their relationships by year's end. The opposite was true when their partners had higher selfregard. Also, individuals reported relatively less destructive conflicts after 4 months the rosier their partners' self-regard at Time 1.

Just as having a partner with a relatively positive self-concept slowed the waning of goodwill apparent in the general sample, holding positive illusions about the self also appeared to buffer the effects of time. Men with rosier self-images at Time 1 reported relatively more satisfaction 12 months later, whereas men with weaker self-images suffered greater declines in happiness. Similar effects emerged (from Time 1 to Time 2) for both men and women when Rosenberg's (1965) Self-Esteem Scale was used as an index of self-models. Intimates with rosier initial self-regard also reported relatively less destructive conflicts as the year progressed. Such effects also emerged concurrently: Individuals more secure in their own senses of self consistently reported less frequent and destructive conflicts. As these collected findings about the self illustrate, actors' and partners' high self-regard helps sustain positive sentiment as relationships progress, whereas personal insecurities appear to pose a latent vulnerability-a theme we will return to shortly.

Turning to a different reality constraint, unfulfilled ideals predicted certain (but limited) difficulties as these romances developed, particularly for women. Both men and women reported more destructive conflicts at Time 2 the more their partners fell short of their ideals. As time passed, women reported larger increases in destructive conflicts by Time 3 the further men fell from their ideals at Time 1 . Similar but weaker effects emerged predicting women's later reports of decreased satisfaction. Although women's ideals began to act as harsh standards as time passed (e.g., Higgins, 1987), men's ideals continued to act largely as positive filters, leading them to see only the best in their relationships. Men with rosier (but unfulfilled) ideals reported relatively less ambivalence and conflict and greater satisfaction as time passed.

\section{Is Idealization (and Its Benefits) Only an Illusion?}

The central challenge in understanding the role of positive illusions in romantic relationships is identifying appropriate benchmarks or baselines for "reality." Distinguishing fact from fiction and idealization from insight requires some knowledge of reality. But in the romantic domain few gold standards exist for measuring objective truths. So we turned to subjective realities-individuals' own views of their virtues and faults-as proxies for truth.

Intimates' impressions did appear illusory in light of their partners' realities. But can this definition of reality be trusted? Perhaps partners are actually being overly humble in their selfdepictions, describing themselves less virtuously than they actually believe themselves to be. Using such modest (and insincere) self-depictions as reality baselines would then overestimate the evidence for idealization and its benefits. That is, the apparent benefits of illusions might actually represent the benefits of having a humble, self-effacing partner.

Several points argue against this humility account of illusions. Considerable evidence suggests that biases in self-reports tend toward self-aggrandizement rather than self-effacement (Taylor \& Brown, 1988). As an illustration of this bias, these dating intimates described themselves much more virtuously than they described the typical partner. Also, they tended to see their own attributes as ideal. Further analyses revealed that intimates' own self-images structured changes in their later models of the ideal partner, which also suggests that their selfdepictions were less than humble. Most critical, greater humility actually dampened later well-being: Actors' satisfaction declined most and doubts increased most when partners were more self-deprecating.

Maybe, though, idealization simply reflects discernment. After all, apparent illusions did forecast the future of these relationships. A year later in these romances, intimates who idealized one another more initially were less likely to break up, reported fewer conflicts, and were less troubled by any nagging doubts or reservations. Undoubtedly, these beneficial effects in part reflect the possibility that intimates who idealize more are in objectively better relationships.

The more intriguing possibility is that positive illusions function as goals or prophecies that have self-fulfilling effects over time. If this is the case (as the present findings suggest), spurious signs of discernment or insight might sometimes result from idealization. For instance, actors' impressions changed in response to the "real" partners' attributes, suggesting that insight increased over time. But being idealized changed self-concepts in the direction of a partner's illusions. Greater insight might have resulted, then, in part because individuals accurately perceived the partners they created by idealizing them (cf. Kelley $\&$ Stahelski, 1970). Similarly, idealization might lessen later conflicts, not because intimates who idealize one another are more compatible but because they are more likely to excuse a partner's misdeeds and thereby avert conflicts. Rather than adopting either extreme viewpoint, the most reasonable position to take is that idealization coexists with some degree of insight. That is, intimates base perceptions on a "kernel" of relationship truth but construe this reality in the most positive possible light.

Self-deception or other-deception? Intimates in satisfying, stable relationships seem to be deceiving themselves (at least to some extent), projecting images of the ideal partner onto their own partner. And later, they even adjust their ideals to accommodate less than perfect partners. Is it possible, though, that individuals are actually trying to deceive more public audiences? That is, can a general social desirability bias account for the findings?

According to this account, some of the apparent benefits of idealization might simply result from certain people's tendency to depict themselves and their partners in a desirable light-a Pollyanna effect. Such a bias could stem from intentional distortions or habitual tendencies to use high versus low points on a scale. Ratings of the typical partner likely capture such habitual tendencies to respond to scaled items in particular ways. When we controlled for individuals' perceptions of the typical partner 
(in unreported analyses), idealizing a partner and being idealized still predicted greater well-being concurrently. And idealization still retained its benefits over time. All of the reported longitudinal effects remained significant when we controlled for individuals' general tendency to describe others in a more or less positive light.

But any tendencies toward socially desirable responding might be specific to depictions of the self and the relationship (and not surface in ratings of the typical partner). However, global reports of satisfaction undoubtedly capture individuals' tendencies to distort the quality of their relationships to a public audience. And when we controlled for satisfaction, idealization still retained its benefits. For instance, idealizing and being idealized predicted less concurrent conflict and ambivalence even when we controlled for satisfaction. All of the longitudinal benefits of idealization also survived this very stringent test. Idealizing a partner and being idealized predicted fewer later disappointments (as indexed by conflicts and doubts) and self-concept change even when we controlled for both actors' and partners' satisfaction. The evidence for the interpersonal benefits of idealization also rivals a social desirability account. A skeptic would have to argue that intimates pair on the basis of social desirability to explain why intimates are happier when their partners idealize them. However, the near-zero correlation between partners' self-images suggests that this type of assortative mating does not occur. Finally, idealization even predicted a behavioral criterion-the relationship's stability-that is less vulnerable to efforts at self- or other-deception.

We believe that this collection of arguments provides persuasive evidence that positive illusions have beneficial effects on developing romances that are simply not accounted for by more amorphous feelings of satisfaction, simple desires to present a romance in a desirable light to a public audience, or simple biases toward positive or negative responding. Instead, a certain degree of self-deception appeared to characterize satisfying, stable dating relationships.

What is the "real" causal model? In our original model, we pretended that certain causal paths existed-namely, that selfmodels structure ideals, that self-models and ideals structure perceptions of a partner, and that the resulting illusions determine well-being (see Figure 1). The longitudinal data allowed us to examine both the existence and direction of these hypothesized causal links. Our analyses (both reported and unreported) revealed strong support for this basic model. For instance, unreported analyses revealed that models of self shaped later ideals but that ideals did not alter self-models. And idealization had greater influence shaping later well-being than initial well-being did in altering illusions. However, certain complexities did arise. Ideals changed in response to the attributes intimates perceived in their partners, not vice versa.

In reality, some of the causal pathways are most likely reciprocal in nature and may even fluctuate in strength at different points in a relationship's development. Satisfaction likely shapes idealization as well as resulting from it, for instance. And we indeed found isolated evidence of such reciprocal effects. Also, ideals may change in response to the attributes individuals perceive in their partners as well as provide a filter that shapes these perceptions. This latter link seems particularly plausible because ideals related to perceptions but not to the partner's "real" attributes. To really untangle these causal pathways re- searchers would need to capture developing romances as intimates were becoming acquainted. At this point, for example, images of an ideal partner may structure impressions as individuals try to fill in the gaps in their knowledge about their partners. Only later might individuals begin to accommodate their ideals to reflect the partners they perceive.

\section{Seeking and Sustaining Security: Models of Self, Actual Partners, and Possible Partners}

Writers in symbolic interactionist and attachment traditions argue that perceptions of the self as worthy of love and caring are strongly tied to beliefs about the availability of others and their dispositions in relationship contexts (e.g., Baldwin, 1992; Bartholomew, 1990; Bowlby, 1982; Collins \& Read, 1990; Griffin \& Bartholomew, 1994; Hazan \& Shaver, 1987; M. R. Leary et al., 1995). Such theorizing suggests that individuals more secure in their sense of self-worth should be more likely to make the leap of faith necessary to idealize a partner.

But this assumption has not been uniformly accepted. Freud (1922) argued that individuals project the qualities they wish to see in themselves onto their partners, loving from deficit rather than strength (e.g., Karp, Jackson, \& Lester, 1970; Mathes \& Moore, 1985). In support of this, Dion and Dion (1975) found that individuals with low self-esteem admired their partners more than did individuals with high self-esteem. Also, some evidence suggests that certain individuals with more negative selfmodels, such as intimates with a preoccupied attachment style, are more likely to idealize their partners, at least at first (e.g., Feeney \& Noller, 1991).

In the developing romances we studied, positive self-perceptions were closely tied to more positive ideals and impressions of one's partner, suggesting that self-models do indeed play a role in structuring generous models of others. And time accentuated the effects of self-esteem. Working models of ideal and actual (i.e., perceived) romantic partners grew even rosier when individuals were more secure in their own senses of self-worth. Interpersonal effects of self-esteem were also evident. Intimates had more difficulty sustaining idealizing perceptions when their partners were less sure of their self-worth. As Brickman (1987) argued, the demands of trying to bolster a low-self-esteem partner's self-image may simply become too taxing over time.

Loving from relative strength (or weakness), then, shaped the romantic experience. For instance, positive models of self appeared to protect intimates from some of the inevitabilities of accommodation, such as declining satisfaction and increasing conflict. Actors' reports of frequent, destructive conflicts decreased when their own self-perceptions were rosier initially. Also, in terms of interpersonal effects, actors' well-being suffered more over the year when partners' self-images were weaker initially (perhaps because of the link between poorer self-concepts and greater conflicts). Apart from these direct effects of self, loving from strength had a number of indirect effects on later well-being through its link to idealization. That is, the tendency to idealize and be idealized (that self-confidence afforded) had a variety of beneficial, self-fulfilling effects on these developing romances, as we have discussed.

The present findings help to articulate precisely why constructing (and sustaining) satisfying relationships depends on positive models of self (e.g., Erikson, 1968; Reis \& Shaver, 1988; Rogers, 
1972; Tesser, 1988). As further evidence of the importance of self-esteem, dating intimates who are more secure in their attachment styles tend to be involved in more satisfying, trusting relationships (e.g., Brennan \& Shaver, 1995; Kirkpatrick \& Davis, 1994; Simpson, 1990). Also, dating individuals who are higher in self-esteem tend to be involved in more stable and satisfying relationships (Hegelson, 1994; Hendrick, Hendrick, \& Adler, 1988). Similarly, in longitudinal studies of marriage, intimates' greater neuroticism predicted later dissatisfaction and instability (E. L. Kelly \& Conley, 1987; Kurdek, 1993). These collected findings mirror our own conclusions that dispositional insecurities pose a latent vulnerability in relationships, precisely because such self-doubts interfere with intimates seeing their partners in the most generous, flattering light.

\section{Is Love Blind or Prescient?}

As the romances in the present study developed, intimates who idealized one another more proved to be more prescient than blind. Relationships persisted, satisfaction increased, conflicts were averted, doubts abated, and personal insecurities diminished when individuals idealized their partners and their partners idealized them. Thus, lasting security and confidence appear to depend on intimates seeing the best in one another-overlooking each other's faults and embellishing each other's virtues.

Despite idealization's benefits, certain routes to confidence may be more vulnerable than others (e.g., McGuire \& Papageorgis, 1961; Murray \& Holmes, 1994). For some intimates, not recognizing a partner's self-perceived frailties later tarnished their illusions and dampened satisfaction. We suspect that the nature of the stories intimates construct to defuse concerns about a partner's faults will determine the ultimate resiliency (or fragility) of their illusions. For instance, longitudinal data we have collected suggest that relationship stability depends not just on the strength of intimates' illusions, but on the structure and coherence of the representations that individuals construct to support these idealized images. Individuals who integrate a partner's virtues and faults within compensatory "Yes, buts . ." are actually involved in more stable relationships than individuals who compartmentalize their partners' faults, leaving pockets of doubt (Murray \& Holmes, 1995). In future research we will explore the types of representations most likely to sustain idealization and those most likely to leave intimates vulnerable to disillusionment.

\section{References}

Abetson, R. P. (1959). Modes of resolution of belief dilemmas. Journal of Conflict Resolution, 3, 343-352.

Alicke, M. D. (1985). Global self-evaluation as determined by the desirability and controllability of trait adjectives. Journal of Personality and Social Psychology, 49, 1621-1630.

Aron, A., Aron, E. N., Tudor, M., \& Nelson, G. (1991). Close relationships as including other in the self. Journal of Personality and Social Psychology, 60, 241-253.

Aron, A., Paris, M., \& Aron, E. N. (1995). Falling in love: Prospective studies of self-concept change. Journal of Personality and Social Psychology, 69, 1102-1112.

Baldwin, M. W. (1992). Relational schemas and the processing of social information. Psychological Bulletin, 112, 461-484.

Bartholomew, K. (1990). Avoidance of intimacy: An attachment perspective. Journal of Social and Personal Relationships, 7, 147-178.
Bartholomew, K., \& Horowitz, L. M. (1991 ). Attachment styles among young adults: A test of a four-category model. Journal of Personality and Social Psychology, 61, 226-244.

Baumeister, R. F., \& Leary, M. R. (1995). The need to belong: Desire for interpersonal attachments as a fundamental human motivation. Psychological Bulletin, 117, 497-529.

Baumeister, R. F., \& Tice, D. M. (1986). Four selves, two motives, and a substitute process self-regulation model. In R. F. Baumeister (Ed.), Public self and private self (pp. 63-74). New York: Springer-Verlag.

Bentler, P. M. (1990). Comparative fit indexes in structural models. Psychological Bulletin, 107, 238-246.

Bowlby, J. (1977). The making and breaking of affectional bonds. British Journal of Psychiatry, 130, 201-210.

Bowlby, J. (1982). Attachment and loss: Vol. 1. Attachment. London: Hogarth Press.

Bradbury, T. N., \& Fincham, F. D. (1990). Attributions in marriage: Review and critique. Psychological Bulletin, 107, 3-33.

Braiker, H. B., \& Kelley, H. H. (1979). Conflict in the development of close relationships. In R. L. Burgess \& T. L. Huston (Eds.), Social exchange in developing relationships (pp. 135-168). New York: Academic Press.

Brehm, S. S. ( 1988). Passionate love. In R. J. Sternberg \& M. L. Barnes (Eds.), The psychology of love (pp. 232-263). New Haven, CT: Yale University Press.

Brennan, K. A., \& Shaver, P. R. (1995). Dimensions of adult attachment, affect regulation, and romantic relationship functioning. Personality and Social Psychology Bulletin, 21, 267-283.

Brickman, P. (1987). Commitment, conflict, and caring. Englewood Cliffs, NJ: Prentice-Hall.

Brown, J. D. (1986). Evaluations of self and others: Self-enhancement biases in social judgment. Social Cognition, 4, 353-376.

Christensen, A., \& Heavey, C. L. (1993). Gender differences in marital conflict: The case of the demand/withdraw interaction pattern. In $\mathrm{S}$. Oskamp \& M. Costanzo (Eds.), Gender issues in contemporary society (pp. 113-141). Newbury Park, CA: Sage.

Collins, N. L., \& Read, S. J. (1990). Adult attachment, working models, and relationship quality in dating couples. Journal of Personality and Social Psychology, 58, 644-663.

Dion, K. L., \& Dion, K. K. (1975). Self-esteem and romantic love. Journal of Personality, 43, 39-57.

Dunning, D., \& McElwee, R. O. (1995). Idiosyncratic trait definitions: Implications for self-description and social judgment. Journal of Personality and Social Psychology, 68, 936-946.

Dunning, D., Meyerowitz, J. A., \& Holzberg, A. D. (1989). Ambiguity and self-evaluation: The role of idiosyncratic trait definitions in selfserving assessments of ability. Journal of Personality and Social Psychology, 57, 1082-1090.

Epstein, S. ( 1982). Conflict and stress. In L. Goldberger \& S. Breznitz (Eds.), Handbook of stress (pp. 49-68). New York: Free Press of Macmillan.

Erikson, E. H. (1968). Identity: Youth and crisis. New York: Norton.

Feeney, J. A., \& Noller, P. (1991). Attachment style and verbal descriptions of romantic partners. Journal of Social and Personal Relationships, 8, 187-215.

Felmlee, D., Sprecher, S., \& Bassin, E. (1990). The dissolution of intimate relationships: A hazard model. Social Psychology Quarterly, 53, 13-30.

Festinger, L. (1957). A theory of cognitive dissonance. Evanston, IL: Row, Peterson.

Freud, S. (1922). Group psychology and the analysis of the ego. New York: Liveright.

Gottman, J. M. (1994). What predicts divorce? The relationship between marital processes and marital outcomes. Hillsdale, $\mathrm{NJ}$ : Erlbaum.

Gottman, J. M., \& Levenson, R. W. (1992). Marital processes predic- 
tive of later dissolution: Behavior, physiology, and health. Journal of Personality and Social Psychology, 63, 221-233.

Greenwald, A. G. (1980). The totalitarian ego: Fabrication and revision of personal history. American Psychologist, 35, 603-618.

Griffin, D., \& Bartholomew, K. (1994). Models of the self and other: Fundamental dimensions underlying measures of adult attachment. Journal of Personality and Social Psychology, 67, 430-445.

Hall, J. A., \& Taylor, S. E. (1976). When love is blind: Maintaining idealized images of one's spouse. Human Relations, 29, 751-761,

Hazan, C., \& Shaver, P. (1987). Romantic love conceptualized as an attachment process. Journal of Personality and Social Psychology, 52, 511-524.

Hegelson, V. S. (1994). The effects of self-beliefs and relationship beliefs on adjustment to a relationship stressor. Personal Relationships, I, 241-258.

Hendrick, S. S., Hendrick, C., \& Adler, N. L. (1988). Romantic relationships: Love, satisfaction, and staying together. Journal of Personality and Social Psychology, 54, 980-988.

Higgins, E. T. (1987). Self-discrepancy: A theory relating self and affect. Psychological Review, 94, 319-340.

Holmes, J. G., \& Rempel, J. K. (1989). Trust in close relationships. In C. Hendrick (Ed.), Review of personality and social psychology: Close relationships (Vol. 10, pp. 187-219). Newbury Park, CA: Sage.

Huston, T. L., \& Chorost, A. F. (1994). Behavioral buffers on the effect of negativity on marital satisfaction: A longitudinal study. Personal Relationships, 1, 223-240.

Janoff-Bulman, R. (1989). Assumptive worlds and the stress of traumatic events: Applications of the schema construct. Social Cognition, 7, 113-136.

Johnson, D. J., \& Rusbult, C. E. (1989). Resisting temptation: Devaluation of alternative partners as a means of maintaining commitment in close relationships. Journal of Personality and Social Psychology, 57, 967-980.

Karney, B. R., Bradbury, T. N., Fincham, F. D., \& Sullivan, K. T. (1994). The role of negative affectivity in the association between attributions and satisfaction. Journal of Personality and Social Psychology, 66, 413-424.

Karp, E. S., Jackson, J. G., \& Lester, D. ( 1970). Ideal-self fulfillment in mate selection: A corollary to the complementary need theory of mate selection. Journal of Marriage and the Family, 32, 269-272.

Kelley, H. H. (1979). Personal relationships: Their structures and processes. Hillsdale, NJ: Erlbaum.

Kelley, H. H., \& Stahelski, A. J. (1970). The social interaction basis of cooperators' and competitors' beliefs about others. Journal of Personality and Social Psychology, I6, 66-91.

Kelly, C., Huston, T. L., \& Cate, R. M. (1985). Premarital relationship correlates of the erosion of satisfaction in marriage. Journal of Social and Personal Relationships, 2, 167-178.

Kelly, E. L., \& Conley, J. J. (1987). Personality and compatibility: A prospective analysis of marital stability and marital satisfaction. Journal of Personality and Social Psychology, 52, 27-40.

Kenny, D. A. (1996). Models of non-independence in dyadic research. Journal of Social and Personal Relationships, 13, 279-294.

Kirkpatrick, L. A., \& Davis, K. E. (1994). Attachment style, gender, and relationship stability: A longitudinal analysis. Journal of Personality and Social Psychology, 66, 502-512.

Kobak, R. R., \& Hazan, C. (1991). Attachment in marriage: Effects of security and accuracy of working models. Journal of Personality and Social Psychology, 60, 861-869.

Kunda, Z. (1987). Motivated inference: Self-serving generation and evaluation of causal theories. Journal of Personality and Social Psychology, 53, 636-647.

Kurdek, L. A. (1993). Predicting marital dissolution: A 5-year prospective longitudinal study of newlywed couples. Journal of Personality and Social Psychology, 64, 221-242.

Leary, M. R., Tambor, E. S., Terdal, S. K., \& Downs, D. L. (1995). Self- esteem as an interpersonal monitor: The sociometer hypothesis. Journal of Personality and Social Psychology, 68, 518-530.

Leary, T. (1957). Interpersonal diagnosis of personality. New York: Ronald Press.

Levinger, G. (1983). Development and change. In H. H. Kelley, E. Berscheid, A. Christensen, J. H. Harvey, T. L. Huston, G. Levinger, E. McClintock, L. A. Peplau, \& D. R. Peterson (Eds.), Close relationships (pp. 315-359). New York: Freeman.

Markman, H. J. ( 1979). Application of a behavioral model of marriage in predicting relationship satisfaction of couples planning marriage. Journal of Consulting and Clinical Psychology, 47, 743-749.

Markman, H. J. (1981). Prediction of marital distress: A five-year follow-up. Journal of Consulting and Clinical Psychology, 49, 760-762.

Mathes, E. W., \& Moore, C. L. ( 1985). Reik's complementarity theory of romantic love. Journal of Social Psychology, 125, 321-327.

McGuire, W. J., \& Papageorgis, D. (1961). The relative efficacy of various types of prior belief-defense in producing immunity against persuasion. Journal of Abnormal and Social Psychology, 62, 327-337.

McNulty, S. E., \& Swann, W. B. (1994). Identity negotiation in roommate relationships: The self as architect and consequence of social reality. Journal of Personality and Social Psychology, 67, 1012-1023.

Murray, S. L., \& Holmes, J. G. (1993). Seeing virtues in faults: Negativity and the transformation of interpersonal narratives in close relationships. Journal of Personality and Social Psychology, 65, 707-722.

Murray, S. L., \& Holmes, J. G. (1994). Story-telling in close relationships: The construction of confidence. Personality and Social Psychology Bulletin, 20, 663-676.

Murray, S. L., \& Holmes, J. G. (1995). When is a fault not a frailty? The structure of resilient representations in dating relationships. Unpublished data, University of Waterloo.

Murray, S. L., Holmes, J. G., \& Griffin, D. (1996). The benefits of positive illusions: Idealization and the construction of satisfaction in close relationships. Journal of Personality and Social Psychology, 70, 79-98.

Murstein, B. I. (1967). Empirical tests of role, complementary needs, and homogamy theories of marital choice. Journal of Marriage and the Family, 29, 689-696.

Murstein, B. I. (1971). Self-ideal-self discrepancy and the choice of marital partner. Journal of Consulting and Clinical Psychology, 37, 47-52.

Reis, H. T., \& Shaver, P. (1988). Intimacy as an interpersonal process. In S. W. Duck (Ed.), Handbook of personal relationships (pp. 367389). New York: Wiley.

Rogers, C. R. (1972). Becoming partners: Marriage and its alternatives. New York: Delacorte.

Rosenberg, M. (1965). Society and the adolescent self-image. Princeton, NJ: Princeton University Press.

Rubin, Z. (1973). Liking and loving: An invitation to social psychology. New York: Holt, Rinehart \& Winston.

Rusbult, C. E., Verette, J., Whitney, G. A., Slovik, L. F., \& Lipkus, I. (1991). Accommodation processes in close relationships: Theory and preliminary research evidence. Journal of Personality and Social Psychology, 60, 53-78.

Scheier, M. F., \& Carver, C. S. (1992). Effects of optimism on psychological and physical well-being: Theoretical overview and empirical update. Cognitive Therapy and Research, 16, 201-228.

Schlenker, B. R. (1986). Self-identification: Toward an integration of the private and public self. In R. F. Baumeister (Ed.), Public self and private self (pp. 21-62). New York: Springer-Verlag.

Simpson, J. A. (1987). The dissolution of romantic relationships: Factors involved in relationship stability and emotional distress. Journal of Personality and Social Psychology, 53, 683-692.

Simpson, J. A. (1990). Influence of attachment styles on romantic relationships. Journal of Personality and Social Psychology, 59, 971980.

Simpson, J. A., Ickes, W., \& Blackstone, T. (1995). When the head pro- 
tects the heart: Empathic accuracy in dating relationships. Journal of Personality and Social Psychology, 69, 629-641.

Snyder, M., \& Swann, W. B. ( 1978). Behavioral confirmation in social interaction: From social perception to social reality. Journal of Experimental Social Psychology, 14, 148-162.

Snyder, M., Tanke, E. D., \& Berscheid, E. (1977). Social perception and interpersonal behavior: On the self-fulfilling nature of social stereotypes. Journal of Personality and Social Psychology, 35, 656-666.

Swann, W. B. (1987). Identity negotiation: Where two roads meet. Journal of Personality and Social Psychology, 53, 1038-1051.

Swann, W. B., De La Ronde, C., \& Hixon, J. G. (1994). Authenticity and positive strivings in marriage and courtship. Journal of Personality and Social Psychology, 66, 857-869.

Swann, W. B., Hixon, J. G., \& De La Ronde, C. (1992). Embracing the bitter "truth": Negative self-concepts and marital commitment. Psychological Science, 3, 118-121.

Taylor, S. E., \& Brown, J. D. (1988). Illusion and well-being: A social psychological perspective on mental health. Psychological Bulletin, 103, 193-210.

Taylor, S. E., Collins, R. L., Skokan, L. A., \& Aspinwall, L. G. (1989). Maintaining positive illusions in the face of negative information: Getting the facts without letting them get to you. Journal of Social and Clinical Psychology, 8, 114-129.
Tesser, A. (1988). Toward a self-evaluation maintenance model of social behavior. In L. Berkowitz (Ed.), Advances in experimental social psychology, (Vol. 21, pp. 181-228). New York: Academic Press.

Thompson, M. M., \& Holmes, J. G. (1995). Ambivalence in close relationships: Conflicted cognitions as a catalyst for change. In R. M. Sorrentino \& E. T. Higgins (Eds.), Handbook of motivation and cognition (Vol. 3, pp. 497-530). New York: Guilford Press.

Thompson, M., Zanna, M. P., \& Griffin, D. W. (1995). Let's not be indifferent about attitudinal ambivalence. In R. E. Petty \& J. A. Krosnick (Eds.), Attitude strength: Antecedents and consequences (pp. 361-386). Hillsdale, NJ: Erlbaum.

Tice, D. M. (1992). Self-concept change and self-presentation: The looking glass self is also a magnifying glass. Journal of Personality and Social Psychology, 63, 435-451.

Van Lange, P. A. M., \& Rusbult, C. E. (1995). My relationship is better than-and not as bad as-yours is: The perception of superiority in close relationships. Personality and Social Psychology Bulletin, 21, 32-44.

Weinstein, N. D. ( 1980). Unrealistic optimism about future life events. Journal of Personality and Social Psychology, 39, 806-820.

Wiggins, J.S. (1979). A psychological taxonomy of trait-descriptive terms: The interpersonal domain. Journal of Personality and Social Psychology, 37, 395-412.

\section{Appendix}

Positive Illusions and Negativity at Times 1, 2, and 3: Pooled, Standardized Path Coefficients

\begin{tabular}{lccr}
\hline \multicolumn{1}{c}{ Path } & Time 1 & Time 2 & Time 3 \\
\hline & Predicting actor's reports of conflict & \\
i and i': Partner's self-image & $.130^{* *}$ & .034 & .121 \\
f and $\mathbf{f}^{\prime}$ : Actor's self-image & $-.172^{* *}$ & $-.202^{* *}$ & -.043 \\
g and $\mathbf{g}^{\prime}$ : Actor's ideals & .091 & .026 & .031 \\
$\mathbf{h}$ and $\mathbf{h}^{\prime}:$ Projected illusions & $-.388^{* * *}$ & $-.391^{* * *}$ & $-.456^{* * *}$ \\
j and $\mathrm{j}^{\prime}:$ Reflected illusions & $-.223^{* * *}$ & $-.147^{*}$ & $-.364^{* * *}$ \\
\hline
\end{tabular}

Predicting actor's reports of destructive conflict styles

\begin{tabular}{lccc}
$\mathbf{i}$ and $\mathrm{i}^{\prime}:$ Partner's self-image & .009 & -.030 & $.173^{* *}$ \\
$\mathbf{f}$ and $\mathbf{f}^{\prime}:$ Actor's self-image & $-.198^{* * *}$ & $-.313^{* * *}$ & -.002 \\
$\mathbf{g}$ and $\mathbf{g}^{\prime}:$ Actor's ideals & $.164^{* * *}$ & $.258^{* * *}$ & -.006 \\
h and $\mathbf{h}^{\prime}:$ Projected illusions & $-.532^{* * *}$ & $-.573^{* * *}$ & $-.694^{* * *}$ \\
j and $\mathrm{j}^{\prime}:$ Reflected illusions & $-.170^{* * *}$ & $-.217^{* * *}$ & $-.253^{* * *}$ \\
\hline
\end{tabular}

Predicting actor's reports of ambivalence

i and i: Partner's self-image $f$ and $f^{\prime}$ : Actor's self-image $\mathbf{g}$ and $\mathbf{g}$ ': Actor's ideals h: Female's projected illusions $h^{\prime}$ : Male's projected illusions j and j: Reflected illusions

$$
\begin{aligned}
& .247^{* * *} \\
& -.086 \\
& -.048 \\
& -.363^{* * *} \\
& -.363^{* * *} \\
& -.253^{* *}
\end{aligned}
$$

$$
\begin{aligned}
& -.017 \\
& -.139 \\
& .167^{*} \\
& -.354^{* * *} \\
& -.674^{* * *} \\
& -.094
\end{aligned}
$$

$.163^{*}$

.064

.093

$-.601^{* * *}$

$-.601^{* * *}$

$-.276^{* * *}$

Note. See Figure 1 for paths. Time 1 conflict: goodness-of-fit index $(\mathrm{GFI})=.97$, comparative fit index $(\mathrm{CFI})=.99, \chi^{2}(14, N=121)=15.65, n s$. Time 2 conflict: $\mathrm{GFI}=.94, \mathrm{CFI}=.97, \chi^{2}(14, N=73)=20.83$, $n s$. Time 3 conflict: $\mathrm{GFI}=.96, \mathrm{CFI}=1.0, \chi^{2}(14, N=58)=9.05$, ns. Time 1 destructiveness: $\mathrm{GFI}=.97$, $\mathrm{CFI}=.99, \chi^{2}(14, N=121)=18.12, n s$. Time 2 destructiveness: $\mathrm{GFI}=.94, \mathrm{CFI}=.98, \chi^{2}(14, N=73)=$ $18.45, n s$. Time 3 destructiveness: $\mathrm{GFI}=.97, \mathrm{CFI}=1.0, \chi^{2}(14, N=58)=7.41$, ns. Time 1 ambivalence: $\mathrm{GFI}=.98, \mathrm{CFI}=1.0, \chi^{2}(14, N=121)=11.70, n s$. Time 2 ambivalence: $\mathrm{GFI}=.97, \mathrm{CFI}=1.0, \chi^{2}(13, N$ $=73)=9.74, n s$. Time 3 ambivalence: $\mathrm{GFI}=.92, \mathrm{CFI}=.96, \chi^{2}(14, N=58)=20.74, n s$.

${ }^{*} p<.10{ }^{* * *} p<.05 . \quad{ }^{* * *} p<.01$.

Received June 20, 1995

Revision received July 15, 1996

Accepted July 30, 1996 